\title{
Influence of Coarse Aggregate Parameters and Mechanical Properties on the Abrasion Resistance of Concrete in Hydraulic Structures \\ DOI:
}

10.1061/(ASCE)MT.1943-5533.0003860

\section{Document Version}

Accepted author manuscript

Link to publication record in Manchester Research Explorer

Citation for published version (APA):

Omoding, N., Cunningham, L., \& Lane-Serff, G. F. (2021). Influence of Coarse Aggregate Parameters and Mechanical Properties on the Abrasion Resistance of Concrete in Hydraulic Structures. Journal of Materials in Civil Engineering, 33(9), 1-14. [0003860]. https://doi.org/10.1061/(ASCE)MT.1943-5533.0003860

Published in:

Journal of Materials in Civil Engineering

\section{Citing this paper}

Please note that where the full-text provided on Manchester Research Explorer is the Author Accepted Manuscript or Proof version this may differ from the final Published version. If citing, it is advised that you check and use the publisher's definitive version.

\section{General rights}

Copyright and moral rights for the publications made accessible in the Research Explorer are retained by the authors and/or other copyright owners and it is a condition of accessing publications that users recognise and abide by the legal requirements associated with these rights.

\section{Takedown policy}

If you believe that this document breaches copyright please refer to the University of Manchester's Takedown Procedures [http://man.ac.uk/04Y6Bo] or contact uml.scholarlycommunications@manchester.ac.uk providing relevant details, so we can investigate your claim.

\section{OPEN ACCESS}




\section{INFLUENCE OF COARSE AGGREGATE PARAMETERS AND MECHANICAL PROPERTIES ON THE ABRASION RESISTANCE OF CONCRETE IN HYDRAULIC STRUCTURES}

Nicholas Omoding, MSc ${ }^{1}$, Lee S. Cunningham, PhD, CEng, MASCE ${ }^{2}$, Gregory F. Lane-Serff, $\mathrm{PhD}^{3}$. ${ }^{1}$ Doctoral Student, Department of Mechanical, Aerospace and Civil Engineering (MACE), University of Manchester, M13, 9PL, Manchester, UK. Email: nicholas.omoding@manchester.ac.uk

${ }^{2}$ Senior Lecturer, Department of MACE, University of Manchester, M13 9PL, Manchester, UK. Email:

lee.scott.cunningham@manchester.ac.uk

${ }^{3}$ Senior Lecturer, Department of MACE, University of Manchester, M13 9PL, Manchester, UK. Email: gregory.f.lane-serff@manchester.ac.uk

\section{ABSTRACT}

The objective of this experimental investigation is to use the ASTM C1138 (underwater) test method to investigate the influence of the quantity and type of coarse aggregates on the hydrodynamic abrasion resistance of concrete. Thereafter, relationships between the abrasion resistance of concrete with its principal mechanical properties are comparatively examined. It is found that the use of natural coarse aggregates to replace fine aggregates by up to $25 \%$ does not significantly affect concrete abrasion performance but the use of recycled tyre rubber aggregates with aspect ratios of $\sim 4$ to replace $25 \%$ of natural coarse aggregates increases abrasion resistance by up to $64 \%$ depending on the test duration. Further, concretes produced with natural rounded coarse aggregates of $10 \mathrm{~mm}$ significantly outperformed those with angular $20 \mathrm{~mm}$ maximum particle size at all test durations by up to $57 \%$. Finally, for the concrete mixtures tested, results indicate that tensile splitting strength is a superior parameter to compressive strength for prediction of concrete abrasion resistance in the ASTM C1138 test and the relations developed for the concretes tested predicted percentage abrasion loss within the margin of $\pm 0.5 \%$.

\section{Keywords}

Abrasion resistance; rubber aggregates; mechanical properties; hydraulic structures.

\section{INTRODUCTION}

In recent years, there has been increased concern about the durability of concrete structures exposed to the action of water-transported coarse sediments such as hydroelectric dam spillways and stilling basins, coastal defences, navigation locks, bridge aprons etc. The concrete surfaces of these structures 
are prone to disintegration on interaction with hard-coarse sediments carried by the flow in a process termed as hydrodynamic abrasion or abrasion-erosion (ACl Committee 207 2017). The damage inflicted on the affected surfaces not only reduces section thickness through sustained material loss over time but can also incite other modes of structural degradation like corrosion of embedded rebar (Cunningham et al. 2015; Omoding et al. 2020). Figure 1 shows abraded stepped revetment armour units which form the coastal defences at Cleveleys in the North West of England after circa 15 years of exposure to abrasion by pebbles moved by breaking ocean waves. The consequences of this phenomenon include higher safety risks, increased maintenance expenditure due to frequent repair needs and an overall reduction in the service life of such strategic infrastructure. Therefore, in the selection of concrete mixtures used for the construction of new and repair of existing hydraulic structures situated in abrasive environments, it is important that a thorough assessment of their hydrodynamic abrasion resistance is undertaken.

Several test methods exist for evaluation of concrete performance in different abrasive environments but the underwater method developed by (Liu 1981) standardised as (ASTM C1138 2012) and the ring method (Kang et al. 2012; SL 352 2006) are particularly recommended for hydrodynamic abrasion. In the underwater test (ASTM C1138 2012), also referred to as the steel ball method (SL 352 2006), a concrete disc (300 x $100 \mathrm{~mm}$ [ $\phi \mathrm{x}$ thickness]) is subjected to the abrasive action of 70 chrome steel balls of diameters; $25.4 \mathrm{~mm}$ (10 Nos), $19.1 \mathrm{~mm}$ (35 Nos) and $12.7 \mathrm{~mm}$ ( $25 \mathrm{Nos}$ ). The steel balls are moved by water agitated by an immersed paddle rotating at a speed of $1200 \mathrm{rpm}$. In testing normalperformance concretes (NPC), abrasion is measured as mass loss at 12-hour intervals for a total duration of 72 hours. However, this duration can be extended up to 120 hours for high-performance concretes (HPC) because these do not suffer abrasion damage within the standard 72-hour test period sufficient to make meaningful comparisons of different mixtures (Horszczaruk 2005; Sonebi and Khayat 2001). In the ring method, sand ( 0.4 to $2 \mathrm{~mm}$ diameter) is used as the abrasive charge with the solids/water mixture proportioned at a ratio of 1:4. This mixture is contained in the annulus of a ringshaped concrete sample and agitated using a paddle rotating at a speed of about $2700 \mathrm{rpm}$ to cause abrasion of vertical sides of the annulus. The mass loss in the concrete sample is measured at 15minute intervals over a test period of 60 minutes. Finally, hydrodynamic abrasion performance of concrete is then reported as the rate of mass loss per unit area (Kang et al. 2012; SL 352 2006). Based on the size of the abrasive charge adopted, the ring test method is more suited for performance 
assessment of concrete whose field operating environment is dominated by sand-sized $(0.05-2 \mathrm{~mm})$ sediments on the (Wentworth 1922) scale. In contrast, the ASTM C1138 test is recommended for testing concrete exposed to abrasion by coarse sediments i.e., pebbles (2-64 mm) and cobbles (64-256 $\mathrm{mm}$ ). Qualitative similarities have been observed in the nature of damage exhibited by concrete surfaces abraded in the ASTM C1138 test to those in field conditions for the cases of hydroelectric dam stilling basins (Kryžanowski et al. 2009) and stepped coastal revetment armour units (Cunningham et al. 2015) both of which were abraded by coarse sediments. Since severe hydrodynamic abrasion damage in concrete is more prevalent when flowing sediments are within the pebble and cobble size range, many researchers have used the ASTM $\mathrm{C} 1138$ test method to investigate the resistance of concrete. These studies have focussed on understanding factors that influence the performance of both normal and high-strength concretes to identify the most abrasion resistant. These factors include compressive strength, water to binder ratio, coarse aggregate type (Horszczaruk 2005; Liu 1981; Sonebi and Khayat 2001), fine rubber aggregate use (Kang et al. 2012; Kryžanowski et al. 2009), supplementary cementitious materials, steel and synthetic fibre addition (Horszczaruk 2009; Kryžanowski et al. 2009; Liu and McDonald 1981; Sonebi and Khayat 2001), and surface finishing (Liu 1981), etc.

(Liu 1981) undertook a thorough investigation of the ASTM C1138 abrasion resistance of 20 concrete mixtures with cylinder compressive strengths of 22 to $69 \mathrm{MPa}$ at 28 days, and water to cement ratios of 0.33 to 0.72 . The mixtures were produced with ordinary Portland cement (ASTM C150 1978) and different coarse aggregate types, i.e. trap rock, chert, limestone, siliceous gravel, quartzite, granite and blast-furnace slag. The results showed that for the same coarse aggregate type, the average 72-hour abrasion loss decreased with reduced water to cement ratio and increased compressive strength. The study also concluded that for the same water to cement ratio, mixtures made of hard coarse aggregates based on Mohs hardness scale such as chert (6.6) performed much better than those with comparatively softer aggregates such as limestone (3.5). Whilst the Mohs hardness test is only qualitative in nature, strong correlations exist with Vickers micro-indentation tests in the case of minerals (Young and Millman 1964) thus it provides a rapid method for assessing the quality of rocks used as coarse aggregates in abrasive environments. Although (Liu 1981) also reported the flexural strength of the concretes adopted, their relationship with abrasion resistance was not evaluated and neither was the influence of the quantity of coarse aggregates. A recent review by the authors 
(Omoding et al. 2020) postulated on the significance of concrete tensile behaviour on the mechanisms by which material is removed from the surface during the abrasion process. The importance of coarse aggregate content has been underscored by (Choi and Bolander 2012) who observed increased abrasion resistance of concretes with high ratios of exposed coarse aggregate to total surface areas and (Cunningham et al. 2015) who in contrast reported concretes with high coarse aggregate contents exhibited lesser abrasion resistance due to poor particle packing.

(Horszczaruk 2005) tested the ASTM C1138 abrasion resistance of 9 concretes with water to cementitious materials ratios that ranged from 0.26 to 0.27 and cylinder compressive strengths varying from 74 to $116 \mathrm{MPa}$. The concretes were produced using basalt coarse aggregates with maximum particle sizes of $8 \mathrm{~mm}$ and $16 \mathrm{~mm}$ and dosages that varied from 1006 to $1279 \mathrm{~kg} / \mathrm{m}^{3}$. Two steel fibre types $(0.5 \times 30 \mathrm{~mm}[\varphi \times L]$ and $1.0 \times 50 \mathrm{~mm}[\varphi \times L])$ were introduced in five concretes at contents of 70 $\mathrm{kg} / \mathrm{m}^{3}$ whilst one mixture incorporated polyvinyl chloride (PVC) fibres of $19 \mathrm{~mm}$ length at a dose of 1.8 $\mathrm{kg} / \mathrm{m}^{3}$. The cement types used were in accordance with the requirements of (BS EN 197-1 2011) for CEM I 52.5R, CEM I 42.5R and CEM III/A 42.5N. The cement contents in concrete were 450 and 470 $\mathrm{kg} / \mathrm{m}^{3}$ and all mixtures contained silica fume at a dose of $10 \%$ (of cement quantity). The ratio of coarse to fine aggregate content ranged from 1.0 to 2.0 while superplasticiser contents were varied from 1 to $2 \%$ (of cement mass) while one concrete mixture contained $112.5 \mathrm{l} / \mathrm{m}^{3}$ of latex. Abrasion losses were measured at 12-hour intervals over a total duration of 120 hours. The findings showed a very strong correlation between concrete abrasion losses with compressive strength. It was also concluded that for concretes with compressive strengths exceeding $80 \mathrm{MPa}$, abrasion loss exhibited a linear relation with time when the initial test duration of 12 to 24 hours was ignored. The use of PVC fibres resulted in improved abrasion resistance but latex addition was not beneficial. (Horszczaruk 2005) also reported the values of modulus of elasticity of the concretes evaluated but no analysis was carried out on its relation with abrasion loss. This research did not present the tensile and flexural strengths of the concretes used.

(Sonebi and Khayat 2001) tested 12 high-strength concretes with 28-day cylinder compressive strengths ranging from 58 to $117 \mathrm{MPa}$ using the ASTM C1138 test for durations of $48,72,96$ and 120 hours. The concretes were produced with cement Types 10 and 30 (CAN3-A5-M83 1983) (475 to 498 $\mathrm{kg} / \mathrm{m}^{3}$ ), silica fume $\left(51\right.$ to $\left.55 \mathrm{~kg} / \mathrm{m}^{3}\right)$, limestone and granite coarse aggregates (930 to $\left.1100 \mathrm{~kg} / \mathrm{m}^{3}\right)$. The water to binder ratios varied from 0.24 to 0.30 while coarse to fine aggregate content ratios ranged from 

respectively were added in dosages of 58 to $60 \mathrm{~kg} / \mathrm{m}^{3}$ to four mixtures and latex at concentrations of 12 to $15 \%$ of cement mass was introduced in five concretes. The investigation concluded that there was a good correlation between 72-hour abrasion losses and those measured at 48, 96 and 120 hours. Further, fibre and latex addition did not significantly enhance abrasion resistance.

More recently, the sharp increase in the amount of rubber tyre waste worldwide has resulted in attempts to find its uses in the construction industry in order to achieve environmental sustainability. Besides studies that have investigated the possible use of recycled rubber particles in concrete for conventional construction, researchers (Kang et al. 2012; Kryžanowski et al. 2009) have also explored the performance of rubber-aggregate concretes in abrasive hydraulic environments.

(Kang et al. 2012) used the ASTM C1138 method to test the abrasion resistance of concrete mixtures containing $1 \mathrm{~mm}$ and $2.36 \mathrm{~mm}$ crumb rubber aggregate additions in proportions of 9 to $18 \%$ and 6 to $9 \%$ of the cement content respectively. The concretes tested had a constant water to cement ratio of 0.4 and the amount of ordinary Portland cement (PO-42.5) (GB175 2007) was maintained at $400 \mathrm{~kg} / \mathrm{m}^{3}$. Limestone coarse aggregates with a maximum particle size and concentration of $31.5 \mathrm{~mm}$ and 1213 $\mathrm{kg} / \mathrm{m}^{3}$ respectively were used in all mixtures. Further, the ratio of the coarse to fine aggregate content was kept at 1.86 and all mixtures incorporated $2.8 \mathrm{~kg} / \mathrm{m}^{3}$ superplasticiser. The results revealed that abrasion resistance significantly improved with increased amounts of crumb rubber regardless of their size. Concretes with $1 \mathrm{~mm}$ rubber particles outperformed those with $2.36 \mathrm{~mm}$ at the same crumb rubber content. However, compressive strength generally suffered a reduction when rubber aggregates were added to concrete. This deleterious effect was more notable in mixtures with $1 \mathrm{~mm}$ rubber particles. (Kryžanowski et al. 2009) also used the ASTM C1138 method to test the abrasion of resistance of concretes with a water to cement ratio of 0.42 in which $9.5 \%$ of sand (by volume) was replaced with crumb rubber particles with a maximum particle size of $4 \mathrm{~mm}$. The concretes were produced with cement $\left(450 \mathrm{~kg} / \mathrm{m}^{3}\right)$ that conformed with the requirements of (BS EN 197-1 2011) for CEM IIA-S 42.5R, natural river sand (30.6-33.6\% of total aggregate volume), crushed gravel comprising of $65 \%$ carbonate rocks (56.9-69.4\% of total aggregate volume) and polypropylene micro-fibres ( $0.05-0.10 \%$ of volume) and a dry polymer portion (5-10\% of cement mass). The results demonstrated that use of crumb rubber as a replacement for fine aggregates in concrete improved its abrasion resistance by factors of over 4 and 3 at test ages of 90 and 900 days respectively. However, the enhanced abrasion performance was 
attained at the detriment of compressive strength and modulus of elasticity both of which suffered reductions. Based on the two studies which have used fine rubber particles, it is unclear whether similar degrees of abrasion resistance increments can be achieved when coarse crumb rubber is used and introduced as a replacement for natural coarse aggregates.

In summary, several studies have investigated the hydrodynamic abrasion resistance of concretes of various compositions and identified governing parameters. Many studies have concluded that concrete abrasion resistance is directly related to its compressive strength but this is untrue for rubber-aggregate concretes. This suggests that other mechanical properties such as tensile splitting strength, flexural strength and flexural toughness could be more suited for modelling concrete abrasion resistance. However, to date, there are no studies in which the performance of all the major mechanical properties of concrete are systematically compared to identify the best predictor parameter for its hydrodynamic abrasion resistance. The effects of coarse aggregate content and type, as well as alternative approaches of introducing rubber aggregates to concrete on abrasion resistance also require clarification. Further, past studies have not considered the interactive nature of the hydrodynamic abrasion process or discussed the effect of surface characteristics.

This experimental study sets out to investigate: (1) the influence of coarse aggregate quantity and type on concrete abrasion, (2) the effect of introducing coarse rubber particles as a replacement for natural coarse aggregates in concrete on its abrasion resistance, (3) the relative suitability of compressive, tensile splitting and flexural strengths as well as modulus of elasticity of concrete as parameters for modelling its resistance to hydrodynamic abrasion. In this paper, the effect of natural and rubber coarse aggregates is discussed from the perspective of steel ball-concrete surface interaction.

\section{RESEARCH SIGNIFICANCE}

172 An investigation into the influence of the quantity and type of coarse aggregates, as well as the use of 173 crumb rubber particles on concrete abrasion can aid the specification of effective, economic and sustainable abrasion-resistant concretes in abrasive hydraulic conditions. Also, the identification of the

175 most suitable mechanical property of concrete that best correlates to the abrasion resistance is crucial for both mixture design optimisation and prediction of abrasion losses. Therefore, this study contributes

177 to the development of effective and economical concrete mixtures, as well as abrasion resistance models. 
179 The structure of the paper is as follows. The materials used for concrete production and the rationale for

180 the choice of mixture proportions are discussed followed by the brief description of the experimental test

181 procedures used in the research. The experimental results are then presented together with critical 182 discussions before the main conclusions derived from the results are outlined.

\section{3. EXPERIMENTAL PLAN}

\subsection{Materials}

\subsubsection{Cement}

The study used ordinary Portland cement that complied with the requirements of (BS EN 197-1 2011) for CEM I 42.5 R.

\subsubsection{Aggregates}

Bunter quartzite-Uncrushed orthoquartzite pebbles made up of almost entirely quartz with Mohs hardness of $\sim 7$. The grains ranged from white to red colour due to the varied amounts of iron oxide present. The orthoquartzite pebbles constituted up to $75 \%$ of the particles and the rest were sandstone, basalt and other igneous rocks. The particles exhibited sub-rounded to rounded shapes.

Hornfels-This is the exact coarse aggregate used for the fabrication of pre-cast stepped revetment armour units at Cleveleys (see Figure 1). It was comprised of angular particles of crushed hornfels derived from contact metamorphism of andesite which produced a dense, durable and hard rock with Mohs hardness of $\sim 7$. The hornfels coarse aggregates were obtained from a quarry in Shap, Cumbria, UK. This aggregate is also known commercially as either Shap blue or Shap blue granite. Rubber -As shown in Figure 2, these were elongated recycled rubber tyre particles with an average length and cross-sectional dimension of $\sim 8 \mathrm{~mm}$ and $2 \mathrm{~mm}$ respectively. The rubber aggregates were supplied free from wires by SRC Products Ltd, Stockport, UK.

Fine aggregates_-These were natural river sand particles made of quartzite.

The relative density and water absorption values of the natural aggregates used are presented in Table 1 while Figure 3 shows their grading. requirements of (BS EN 12620 2002) for 10, 20 and $4 \mathrm{~mm}$ maximum particle size respectively. 
Ordinary tap water free from contamination was used.

\subsubsection{Additional concrete making materials}

209

Materials in this category included silica fume, synthetic micro-fibres and a concrete admixture which were used in two specific concretes. The silica fume was supplied in slurry form (50\% solids and $50 \%$ water) by Elkem AS, Norway. The properties of the monofilament, surfactant-coated polypropylenebased micro-fibres used are presented in Table 2. Further, a chloride-free mid-range water reducer (MRWR) based on modified polycarboxylate was also used. Both the synthetic micro-fibres and water reducer were supplied by Sika UK Ltd. These materials were as per those used in the concrete for the aforementioned revetment armour units that form the coastal defences at Cleveleys.

\subsection{Test specimens}

\subsubsection{Concrete mixture design}

The proportioning of constituents of the concretes used in this study is presented in Table 3 . The mixtures adopted incorporate variations in the quantity, shape and size of natural coarse aggregates, introduction of rubber particles and compressive strength. The variation in concrete mixtures were designed to allow a wide range of applicability of the findings and enable the influence of key mixture design parameters to be evaluated. The influence of coarse aggregate quantity was evaluated by considering concrete mixture $\mathrm{C} 1$ as a reference mixture based on which concretes $\mathrm{C} 2$ and $\mathrm{C} 3$ were derived by replacing $15 \%$ and $25 \%$ (by mass) respectively of fine with coarse aggregates. The replacement approach ensured that the total aggregate content was maintained in all the three mixtures. High water to cement ratios were used in mixtures $C 1$ to $C 3$ so as to facilitate the occurrence of coarse aggregate removal by plucking, and thus maximise the effect of coarse aggregate quantity. Concretes C1, C4 and C5 were designed in accordance with BRE guidance (Teychenne et al. 1997) to achieve target cube compressive strengths of 20,35 and $45 \mathrm{MPa}$ so that the performance of concrete specified based on compressive strength is evaluated. The effect of using $25 \%$ (by mass) rubber particles in mixture C6 as replacement for bunter quartzite coarse aggregates was assessed by comparing its performance with that of C5.

Concrete mixture $\mathrm{C} 7$ replicated the specification used in the fabrication of pre-cast units for the stepped coastal defence revetment armour units at Cleveleys in the Northwest of England (Cunningham et al. 
2015). These units, situated in one of the most abrasive environments along the UK coast currently appear to exhibit considerable resilience to abrasive action from pebbles driven by breaking waves. The design of concrete $\mathrm{C} 7$ was consistent with requirements for concretes used in abrasive conditions as set out in (BS 6349-1-4 2013) in that the cube compressive strength exceeded $50 \mathrm{MPa}$, water to binder ratio was less than 0.45 and the minimum binder content was greater than $350 \mathrm{~kg} / \mathrm{m}^{3}$. The compositions of mixtures $\mathrm{C} 7$ and $\mathrm{C} 8$ were only differentiated by entire replacement of hornfels coarse aggregates with bunter quartzite from which the effect of aggregate type, particularly maximum size could be investigated. This was because both aggregates had the same value of Mohs hardness, a critical parameter for concrete abrasion resistance (Liu 1981).

\subsubsection{Fabrication of test specimens}

For each concrete mix, three specimens were made for abrasion, tensile strength, modulus of elasticity and fracture toughness tests while several cubes were cast for compressive strength tests. The manufacture procedure for test specimens was as follows. Concrete constituents were weighed in accordance with the proportions shown in Table 3 and mixed using a rotary-drum mixer. The moulds were lubricated with mould oil prior to placing concrete. For each of the specimens, concrete was placed in three approximately equal layers with compaction using a vibrating table following the placement of each layer. Top surfaces of all specimens were neatly finished with a steel float, covered with a polythene sheet to minimise moisture escape, and then stored in a room maintained at a temperature of $20 \pm 3^{\circ} \mathrm{C}$ for 24 hours. Thereafter, the specimens were demoulded and cured by immersion in a water tank until the age of 28 days when they were removed for various tests.

\subsection{Test procedures}

The study tested hydrodynamic abrasion resistance and its mechanical properties at 28 days.

\subsubsection{Concrete abrasion tests}

The ASTM C1138 method (ASTM C1138 2012) was used to test the resistance of concretes to abrasion for a maximum duration of 72 hours. Three (03) specimens for each concrete mixture were tested, thus a total of 24 were subjected to abrasion in the experimental set-up illustrated in Figure 4.

In this test, a concrete disc test specimen is immersed in a steel cylinder with a diameter of $300 \mathrm{~mm}$. The specimen is abraded by the action of 70 chrome steel ball bearings comprised of 25 Nos of 12.7 $\mathrm{mm}, 35$ Nos of $19.1 \mathrm{~mm}$ and 10 Nos of $25.4 \mathrm{~mm}$. The motion of the abrasive ball bearings is induced by 
the agitation of water using a paddle with a rotating speed of $1200 \mathrm{rpm}$. The changes in test specimen volumes as a result of abrasion were measured at test intervals of 12, 24, 48 and 72 hours. The volumes of the concrete specimen at a given test increment, $t$, was calculated as,

$$
V_{t}=\frac{M_{a}-M_{w}}{\rho_{w}}
$$

where, $M_{a}=$ mass of test specimen in air, $M_{w}=$ mass of test specimen in water and $\rho_{w}=$ density of water. It should be noted that mass was measured to the nearest 1 gram at each test duration while the density of water was assumed to be $1000 \mathrm{~kg} / \mathrm{m}^{3}$. Concrete abrasion loss $\left(\mathrm{V}_{\mathrm{abr}, \mathrm{t}}\right)$ at each test duration is estimated as,

$$
V_{a b r, t}=V_{0}-V_{t}
$$

in which, $V_{o}=$ specimen initial volume (before the test); and $V_{t}=$ specimen volume at a specified test duration. The calculated concrete abrasion at the four test time increments was expressed as a percentage of the initial volume of the test specimen. In this investigation, all the surfaces tested were the bottom as-struck to ensure that the quality of the concrete surface finish and the density was comparable to those exhibited by revetment armour units used in coastal protection. These are often precast units that are cast face-down so that the surface exposed to abrasion is that which was originally in direct contact with the mould (Cunningham et al. 2012, 2015; Cunningham and Burgess 2012). This approach ensures that it is a denser and higher-quality surface finish that is exposed to the aggressive environment, thus minimising the risk of ingress of sulphates and chlorides (Cunningham et al. 2012) which are deleterious to concrete.

\subsubsection{Mechanical properties}

The concrete properties evaluated comprised of the basic mechanical properties i.e. compressive strength, tensile splitting strength and modulus of elasticity, as well as flexural toughness. Table 4 presents the scope of tests on the basic mechanical properties of concrete.

The flexural behaviour of the concretes used was investigated with the three-point bending test using the experimental setup illustrated in Figure 5. The test specimens used were notched prisms that measured $80 \times 150 \times 700 \mathrm{~mm}$ in accordance with (RILEM TC89-FMT 1990) and cast in triplicate for each concrete mixture. The notches of $3.6 \mathrm{~mm} \times 50 \mathrm{~mm}$ (width $\times$ depth) were all cast-in at the bottom of 
the prism mid-span whilst the effective span length was maintained at $600 \mathrm{~mm}$ in all tests. A linear variable displacement transducer (LVDT) attached to the lower side of the beam was used to measure the crack-mouth opening displacement (CMOD) of the prism under load. The specimens were loaded by a displacement-controlled machine at a constant rate of $0.02 \mathrm{~mm} / \mathrm{s}$. The applied loads and respective values of CMOD were continuously recorded until the failure crack propagated throughout the entire concrete section above the notch. The results obtained were used estimate the flexural strength and flexural toughness of concrete. 2009) and expressed in Equation (3).

$$
\sigma_{f}=\frac{3 F L}{2 b d^{2}}
$$

where, $\sigma_{f}=$ flexural strength; $F=$ peak load; $L=$ distance between roller supports; $b=$ width and $d=d e p t h$ of concrete above the notch.

In the flexural strength computation, no adjustment was made to the measured peak load to account for the weight of the concrete section in the notch depth which is absent in the standard (BS EN 12390 2009) test. This is due to the fact that the bending moment induced by its equivalent point load was very small $(<1 \%$ of the measured peak load). Also, the breadths of test specimens were $80 \mathrm{~mm}$ compared to $100 \mathrm{~mm}$ in (BS EN 12390 2009). However, since the effective depth (100 mm) which is critical in bending was consistent with the standard, the small difference in width was deemed not to significantly affect the flexural strength.

307 Flexural toughness-The load and CMOD results from the three-point bending tests were used to calculate the flexural toughness of the concretes used. Flexural toughness was estimated as the total area under the load versus CMOD curve up to a specified value of $0.3 \mathrm{~mm}$. The use of a constant CMOD value of $0.3 \mathrm{~mm}$ in all tests ensured that the work done by the external load was comparable across the concretes examined and the average result of the three test specimens was reported as flexural strength.

\section{TEST RESULTS AND DISCUSSION}


314 In the first step of analysis of test results, the mean values and coefficients of variation (ratio of standard

315 deviation to mean) were used to respectively describe concrete abrasion resistance and the dispersion 316 of test data. Thereafter, it was determined whether or not the differences in the abrasion resistance 317 were statistically significant at $95 \%$ confidence. The $95 \%$ confidence used is consistent with the level 318 generally used to determine characteristic material strength (BS EN 1990 2002). For all the parameters 319 tested, the small sample size of nine for compressive strength and three for the rest of the tests were 320 insufficient to determine whether or not the samples were drawn from a population with a normal 321 distribution. Consequently, nonparametric tests, i.e. Kruskal-Wallis ANOVA and Mann-Whitney tests 322 (Hayter 2012) were used to compare the results of three or more and two concrete mixtures respectively. To perform the Kruskal-Wallis ANOVA test, the data from each sample group is pooled and ranked. Thereafter, the sum of ranks for each sample group is calculated, and the $\mathrm{H}$ statistic computed. The H-statistic follows the Chi-Square $\left(X^{2}\right)$ distribution with degrees of freedom (DF) equal to the number of sample groups minus one (Hayter 2012). The Mann-Whitney test is applicable to twosample unpaired data and is also performed by first pooling and ranking the test data of each sample group. Subsequently, the total ranks sum is determined for each sample group and the U-statistic calculated. In both tests, the $p$-values were estimated and compared with the significance level $(\alpha=0.05)$ to determine whether the differences were statistically significant (Hayter 2012). The aforementioned statistical tests have been successfully applied by various researchers in the field of concrete research

332 (Branston et al. 2016; Cross et al. 2000; Hasparyk et al. 2000; Proverbio 2001).

\subsection{Mechanical properties}

The mechanical properties of the concretes tested at the age of 28 days are summarised in Table 5 . The results presented are the means of three test specimens while the corresponding coefficients of variation (\%) are shown in the parenthesis.

\subsection{Concrete abrasion tests}

338 Figures 6 presents concrete abrasion losses measured at test durations of 12, 24, 48 and 72 hours. 339 The plotted values are the means obtained from three test specimens. 


\subsubsection{Dispersion of abrasion test results}

341 It can be observed in Figure 6 that the measured abrasion loss in the concrete mixtures exhibited 342 inherent deviations from the mean. The deviations were assessed using coefficients of variation of the 343 test data shown in Table 6 for the durations tested.

Table 6 shows that coefficients of variation in abrasion losses varied from 1.6 to $22.2 \%, 7.1$ to $19.4 \%$, 1.3 to 29.2 and 6.1 to $20.4 \%$ at test durations of $12,24,48$ and 72 hours respectively. It is important to note that these values are consistent with those from the few past studies that declared the variability in test data through either coefficients of variation (Sonebi and Khayat 2001), standard deviation (Wang et al. 2018) or reporting the abrasion losses of all the individual test specimens (Liu 1981). An analysis of test results by (Liu 1981) for concretes with cylinder compressive strengths of 22 to 69 MPa showed that maximum coefficients of variations were $57.5 \%, 25.3 \%, 24.1 \%$ and $20.7 \%$ at test periods of $12,24,48$ and 72 hours respectively. These deviations were based on results of 3 specimens for 12 mixtures and 2 specimens for the other two concretes. If the higher value obtained at 12 hours is considered to be an outlier and due to fact that only the matrix layer is abraded in this period, it can be observed that the coefficients of variation in abrasion test data were less than $30 \%$ and thus in agreement with the results of the present investigation. Test results obtained by (Sonebi and Khayat 2001) are also consistent with this assertion. The maximum values of coefficients of variation computed from test results of 3 specimens produced from 12 high-strength concretes with cylinder compressive strengths of 58 to $117 \mathrm{MPa}$ were $25.3 \%, 15.0 \%, 16.1 \%$ and $8.1 \%$ for test durations of 48 , 72, 96 and 120 hours respectively (Sonebi and Khayat 2001). However, remarkably low deviations in abrasion loss measurements were reported by (Wang et al. 2018) at 72 hours for 6 concrete mixtures with cube compressive strengths of 31 to $60 \mathrm{MPa}$ tested at 28,90 and 180 days. The coefficients of variation ranging from 1.0 to $2.6 \%$ were calculated from the reported means and standard deviations of 3 test results.

Based on the analysis of test data from the present investigation together with three other detailed data sets available in literature, it is evident that the ASTM C1138 test is a repeatable test method that produces concrete abrasion loss measurements with maximum coefficients of variation of $\approx 30 \%$. Therefore, in the assessment of the reliability of concrete abrasion resistance models developed from the ASTM C1138 test results, this degree of deviation in test data needs to be taken into account. 


\subsubsection{Influence of concrete mixture design variables}

370 The concrete mixture proportions in Table 3 enabled the analysis of the effect of coarse aggregate quantity and type, as well as the use of rubber particles to be analysed.

\section{Quantity of coarse aggregates}

373 The effect of the quantity of coarse aggregate on concrete abrasion was evaluated from Figure 6 based on the resistance of mixtures $\mathrm{C} 1, \mathrm{C} 2$ and $\mathrm{C} 3$ which had the coarse to fine aggregate ratios of $1.2,1.6$ and 2.1 respectively. At test durations of 12 to 48 hours, increasing the quantity of coarse aggregates by $15 \%$ reduced the mean concrete abrasion loss by about $2 \%$ to $23 \%$. In contrast, mean concrete abrasion loss increased by $18 \%$ at 72 hours due to the $15 \%$ increase in coarse aggregate quantity. The increment of the coarse aggregate content by $25 \%$ in mixture C3 had not effect on mean abrasion loss at 12 hours when compared to $\mathrm{C} 1$. However, increases of about $7 \%$ to $23 \%$ were obtained at 24 to 72 hour test durations. The fact that coefficients of variation in abrasion loss measurements of these concretes shown in Table 6 varied from 3\% to 22\% implies that differences in abrasion loss values were not reliable for evaluating variations in the performance of these mixtures. Therefore, statistical significance of the differences in the abrasion loss was tested using the Kruskal-Wallis ANOVA test at 95\% confidence and results summarised in Table 7.

The results in Table 7 show that at test durations of 12 to 72 hours and at $95 \%$ confidence, abrasion losses in concretes $\mathrm{C} 1, \mathrm{C} 2$ and $\mathrm{C} 3$ were not significantly different $(p>0.05)$.

In normal-strength concretes, the influence of the quantity of coarse aggregates on concrete abrasion resistance could be related to the concept of the aggregate exposure ratio (AER), defined by (Choi and Bolander 2012) as a fraction of the concrete surface area occupied by coarse aggregates. AER is intrinsically related to maximum size, distribution, shape and volume of coarse aggregates within the concrete mixture. Therefore, as the quantity of coarse aggregates is gradually increased, the AER also increases. The implication of this is that more coarse aggregates would be exposed after the disintegration of the matrix surface layer, and consequently become vulnerable to being plucked due to hydrodynamic action. Therefore, the co-operative effect of the grinding and plucking mechanisms would lead to a higher rate of concrete material removal than when only a single abrasion mechanism is present. It would also be expected that plucked coarse aggregate particles deposited on the surface become additional abrasive sediments and thus exacerbate the rate of material loss during the abrasion process. A further effect of coarse aggregate quantity is on the workability of concrete whereby the use 
of large amounts can result in reduced slump due insufficient paste available to coat the coarse

400

401

402

403

404

405

406

407

408

409

410

411

412 aggregate particles. The negligible differences in the abrasion losses in mixtures $\mathrm{C} 1, \mathrm{C} 2$ and $\mathrm{C} 3$ suggests that specification of coarse to fine aggregate quantity ratios of up 2 does not reduce the abrasion resistance of the resultant concretes. The use of more coarse aggregate in concrete without significantly reducing its abrasion performance provides economic benefits. However, (Cunningham et al. 2015) found that in high-strength concretes with cube compressive strengths exceeding $80 \mathrm{MPa}$, increasing the proportion of coarse aggregates in the mixture by $25 \%$ led to $66 \%$ reduction in abrasion resistance. The reduction in resistance in this case was attributed to the poor particle packing in mixtures incorporating higher coarse aggregate quantities (Cunningham et al. 2015). This discrepancy highlights the differences in the effect of coarse aggregate content on the abrasion resistance of normal and high-strength concretes.

Thus, it appears that for both normal and high-strength concretes, no enhancements in abrasion resistance are achieved by specifying coarse aggregate dosages exceeding those required for a compressive strength-based mixture design.

\section{Coarse aggregate type}

The effect of the type of coarse aggregates on concrete abrasion resistance was evaluated from test results of mixtures C7 and C8 in Figure 6. It is observed that on the basis of mean abrasion loss, concrete C8 out-performed $\mathrm{C} 7$ by $57 \%, 46 \%, 32 \%$ and $34 \%$ at test durations of $12,24,48$ and 72 hours respectively. To determine whether or not the abrasion losses in concretes $\mathrm{C} 7$ and $\mathrm{C} 8$ were significantly different, the Mann-Whitney test was used. It was found that at $95 \%$ confidence, the abrasion losses of concrete $\mathrm{C} 7$ tended to be significantly greater than those of concrete $\mathrm{C} 8(U=9, p=0.040)$. This implied that mixture C8 exhibited significantly better abrasion resistance. Based on the 28-day compressive strength, both mixtures $\mathrm{C} 7$ and $\mathrm{C} 8$ can be classified as high-strength concretes and the influence of individual coarse aggregates on the mechanical properties of such concretes has been investigated in the past (De Larrard and Belloc 1997). High-strength concretes are characterised by the matrix and coarse aggregate phases exhibiting similar strengths (ACI Committee 363 2010). On examination of the composition of the abraded material and the topography of the damaged surfaces of both mixtures, no visible plucking of coarse aggregates was noted within the test duration of 72 hours. However, it was evident from the surface topography that coarse aggregate particles were more resistant to abrasion 
than the matrix since the former and latter respectively comprised the crests and troughs of the damaged concrete surface.

430 The low matrix hardness relative to the coarse aggregate phase in both concretes suggests that the differences in abrasion resistance is due to the influence of maximum aggregate size and particle size distribution. Figure 7 presents the combined particle size distribution of the aggregates, i.e. sand and hornfels (C7), and sand and bunter quartzite (C8).

Figure 7 shows that both mixtures $\mathrm{C} 7$ and C8 were produced with gap-graded aggregates, deficient in 5 to $8 \mathrm{~mm}$ particles. However, the two gradings were differentiated by the higher percentage of particles passing the respective sieve sizes in concrete C8 compared to C7. This demonstrates that for the respective sieve size, mixture C8 comprised of higher proportion of small aggregate particles. Further, the maximum aggregate size of mixture $\mathrm{C} 7$ was twice that of $\mathrm{C} 8$. Therefore, it appears that the increase in the proportion of small coarse aggregate particles together with the reduction in the maximum aggregate size increased the abrasion resistance of mixture $\mathrm{C} 8$. This behaviour can be attributed to the dense packing of aggregate particles which also influences the surface areas occupied by the matrix and coarse aggregate particles. These areas are influenced by the maximum size and distribution of coarse aggregate particles. The bound matrix areas in both mixtures presented latent localised zones for rapid abrasion damage owing to their lower hardness and the size of these areas is a function of coarse aggregate size. This surface area of the matrix increases with aggregate size as illustrated in Figure 8 for the case of dry-packed single-sized $10 \mathrm{~mm}$ and $20 \mathrm{~mm}$ idealised spherical aggregates. Therefore, once the coarse aggregate particles have been exposed, the concrete surface transforms into patches of hard (coarse aggregate phase) and soft (matrix phase) areas. With the continued interaction of the mobile steel balls with the softer matrix phase, further abrasion damage will depend on coarse aggregate particle dispersion and the size of abrasives. If an arbitrary matrix area of $8 \mathrm{~mm}$ diameter is considered, the maximum matrix depths accessible by the three steel ball sizes used in the standard ASTM C1138 test are in the ratios of 1.00: 0.61: $0.45(13: 19: 25 \mathrm{~mm} \phi)$. These ratios indicate that at a later stage of the abrasion process, the contribution of 19 and $25 \mathrm{~mm} \phi$ steel balls to abrasion of the cement/sand matrix is greatly diminished. A period then occurs when the large-sized abrasive balls will only participate in abrading the harder coarse aggregate particles whilst the interaction of the small-size balls with both the coarse aggregate particles and matrix endures. The better shelter-effect of 
457 the smaller coarse aggregates on the matrix results in relatively low material removal rates in such

458

459

460

461

462

463

464

465

466

467

468

469

470

471

472

473

474

475

476

477

478

479

480

481

482

483

484

concretes provided the coarse aggregate phase is harder than that of the matrix. This also suggests that there is a relationship between maximum aggregate size and the size of abrasive sediments; better abrasion resistance would be expected when the average size of the abrasive is greater than the maximum aggregate size used. This hypothesis however needs further experimental investigation. Also, provided the values of coarse aggregates' Mohs hardness are comparable, the particle shape does not appear to negatively affect the concrete resistance to abrasion given that mixture C8 produced with sub-rounded to rounded aggregate outperformed $\mathrm{C} 7$ which incorporated angular coarse aggregate particles.

\section{Use of rubber particles to replace coarse aggregates}

The effect of rubber was investigated by replacing the $25 \%$ (by weight) of natural coarse aggregates in concrete mixture C5 with rubber aggregate particles to produce mixture C6. The results presented in Figure 6 show that in comparison with the control mixture (C5), the rubber-aggregate concrete exhibited lower mean abrasion loss. The use of rubber reduced abrasion loss by $3 \%, 42 \%, 57 \%$ and $64 \%$ at $12,24,48$ and 72 hours respectively.

The significance of the difference in the performance of mixtures C5 and C6 was tested with the MannWhitney test. At 12 hours, the abrasion loss in concretes $C 5$ was not significantly greater $(U=6, p>0.05)$ than that of C6. However, at 24, 48 and 72 hours, the abrasion loss of mixture C5 tended be significantly greater than that of $\mathrm{C} 6(U=9, p<0.05)$ at $95 \%$ confidence. Therefore, concrete abrasion resistance improved with the addition of rubber particles from 24 to 72 hours. The similarity in the abrasion resistance of the two concretes at the 12-hour test duration suggests that the structures of the as-struck matrix surface layers for natural and rubber-aggregate concretes were similar. The increase in abrasion resistance at 24,48 and 72 hours due to the addition of rubber particles agrees with the conclusions of previous studies (Kang et al. 2012; Kryžanowski et al. 2009) despite the different approaches used in the introduction of rubber particles and their size. (Kryžanowski et al. 2009) incorporated rubber as replacement for fine aggregates while (Kang et al. 2012) introduced rubber addition to the control concrete mixture and both studies reported abrasion resistance increments of up to $306 \%$ (900 days) and $371 \%$ (28 days) respectively. 
Therefore, the enhanced abrasion resistance exhibited by the rubber-aggregate concrete in the present study confirms that use of rubber to replace coarse aggregates has a consistent effect as to when it is introduced as a replacement for fine aggregates and as an additional material. However, the approach of replacing natural coarse aggregates with rubber appears to produce smaller increments in abrasion resistance of concrete compared to use as a replacement for fine aggregates or as an addition.

Scanning electron microscopy analyses have shown that voids and cracks are prevalent at the interface of rubber aggregate particles and the matrix in comparison to natural aggregates (Thomas et al. 2016). Therefore, the higher abrasion resistance of rubber aggregate concretes may be attributed to the properties of individual rubber particles rather than the quality of their bond with the matrix. In particular, the high energy absorption capacity of rubber (Kang et al. 2012) due to its low modulus of elasticity and large Poisson's ratio (Finnie 1960) means that very limited material can be detached from the surface due to the action of the abrasive steel balls. Further, the interactive nature of the abrasion process which has mostly been ignored in previous studies on rubber aggregate concretes also plays a role. By examining the characteristics of abrasion-damaged surfaces of the rubber-aggregate concrete, it was observed that some elongated rubber particles anchored to the cement/sand matrix provided flexible roughness to the concrete surface. The presence of flexible surface roughness retards flow speeds and increases flow energy dissipation (Carollo et al. 2002; Chen and Kao 2011; Kouwen et al. 1969). Thus,

502 the combination of flexible roughness and roughness due to differential abrasion rates of the coarse aggregates and cement/sand matrix results in reduced speeds of the abrasive steel balls hence minimising material removal. The rubber particles can also shelter the natural coarse aggregates and matrix from direct impact of the abrasive solids.

506 It is also observed that the damaged rubber-aggregate concrete surface appeared less aesthetic 507 compared to that of natural coarse aggregates as compared in Figure 9 for a test duration of 72 hours.

508 This could make rubber-aggregate concretes less desirable for use in abrasive field conditions where 509 the appearance of the concrete surfaces is important such as coastal defences accessible to the public.

510 Other concerns on the use of concretes containing rubber particles in hydrodynamic abrasive conditions 511 relating to their resistance to ultraviolet, chemical and biological degradation, as well as the impact of 512 rubber particles on aquatic and marine life have previously been highlighted by the authors (Omoding et 513 al. 2020). 
514 In summary, regardless of the approach to introducing rubber, rubber-aggregate concretes possess

515 higher abrasion resistance compared to those with only natural aggregate for the same water to cement 516 ratio and cement content. The better resistance exhibited by rubber aggregate concrete is attributable

517 to the combined effect of the high-energy absorption capacity of rubber particles, attenuated flow 518 energy levels which reduce the abrasive power of the steel balls and the sheltering effect of rubber 519 particles on the natural coarse aggregates and cement/sand matrix.

\subsection{Prediction of concrete abrasion resistance}

\subsubsection{Dependence of concrete abrasion loss on mechanical properties}

522 The relationship between abrasion loss and mechanical properties was first investigated by evaluating whether or not there was consistency in the effect of the concrete mixture parameters on concrete abrasion loss and its mechanical properties. Subsequently, regression analysis of the test data was undertaken to propose empirical relations to predict concrete abrasion loss from mechanical properties. Since the abrasion loss of mixtures $\mathrm{C} 1$ to $\mathrm{C} 3$ were not significantly different, the Kruskal-Wallis ANOVA test was used to determine whether or not their mechanical properties were also drawn from the same population. In contrast, since the abrasion loss of mixtures $\mathrm{C} 5$ and $\mathrm{C} 6$, as well as $\mathrm{C} 7$ and $\mathrm{C} 8$ were significantly different, the Mann-Whitney test was used determine whether or not the mechanical properties also exhibited significant differences. The two statistical tests were undertaken at 95\% confidence with the results presented in Table 8, from which analysis of the effect of coarse aggregate quantity and type, as well as rubber particles use as a replacement for natural aggregates was made.

The results in Table 8 indicate that at 95\% confidence, the variation in coarse aggregate content did not have a significant effect on tensile strength, flexural strength and flexural toughness. This is in agreement with the behaviour exhibited by concrete abrasion test results at all test durations $(12,24,48$ and 72 hours. Conversely, the compressive strength and modulus of elasticity results of mixtures $\mathrm{C} 1$ to C3 were shown to be significantly different. Whilst mixture C5 suffered significantly higher abrasion loss, i.e. a low abrasion resistance compared to $\mathrm{C} 6$, at $95 \%$ confidence all the mechanical properties of concrete $\mathrm{C} 6$ tended to be significantly less. This suggests that the abrasion loss of rubber aggregate concretes increases with reduced mechanical properties which contradicts with the behaviour of natural-aggregate concretes whose resistance is mostly enhanced with increased mechanical properties such as compressive strength. As a result, specific empirical models that cater for the beneficial impact of rubber addition will be required for concretes containing rubber aggregates. Due to 
544 this behaviour, the results of the rubber aggregate concrete have been omitted in the regression 545 analysis presented in 4.3.2. In the case of concretes with different types of natural coarse aggregates, 546 mixture $\mathrm{C} 7$ exhibited significantly higher abrasion loss compared to C8 while Table 8 shows that at $95 \%$ 547 confidence, all the mechanical properties of concrete $\mathrm{C} 7$ tended not to be significantly less than those 548 of C8. This discrepancy indicates the limitations of the mechanical properties of concrete tested for 549 defining its abrasion resistance for the range of mixtures examined.

\subsubsection{Regression analysis}

551 The aim of this section is to determine the most appropriate mechanical property for defining the resistance of concrete to hydrodynamic abrasion for the mixtures evaluated. This is undertaken through a comparative evaluation of the relation between abrasion loss and compressive strength, tensile splitting strength, modulus of elasticity, flexural strength and toughness. The first step was to establish the form of relation by fitting of data to linear, power, exponential, logarithmic and polynomial functions and comparing the coefficients of determination $\left(R^{2}\right)$. The form of relation that provided the highest $\mathrm{R}^{2}$ was adopted and tested for significance using an F-test (Hayter 2012). Figures 10 to 14 show the dependence of concrete abrasion on mechanical properties while Table 9 presents the regression equations and statistical significance parameters.

In Table 9, the degrees of freedom (DF) 1 and 2 are for the model and error respectively. Based on the $R^{2}$ values, it was found that polynomial functions produced the best fit for the relationship between abrasion loss and all properties. However, the relation with flexural strength could also be described with a linear function without any significant deterioration in the value of $R^{2}$. A linear relation was thus adopted for flexural strength. Further, Table 9 shows that compressive strength, tensile splitting strength, modulus of elasticity, flexural strength and flexural toughness respectively explained $78 \%$ to $93 \%, 86 \%$ to $97 \%, 44 \%$ to $65 \%, 76 \%$ to $94 \%$ and $71 \%$ to $95 \%$ variation in the abrasion loss of concrete. This suggests that for the concrete mixtures investigated, tensile splitting strength exhibited the best correlation with abrasion loss of concrete when compared to other mechanical properties. The higher $R^{2}$ values obtained for tensile splitting strength agrees with an evaluation of the results of (Horszczaruk and Brzozowski 2017) for the 72-hour abrasion loss for specimens aged 56 days while for 28 day-old specimens, the difference in $R^{2}$ values for compressive and tensile strengths were negligible. Also, marginal differences in $R^{2}$ were observed between compressive strength and modulus of elasticity based on the test data of (Kryžanowski et al. 2009) while results from (Liu 1981) pointed to compressive 
574 strength being superior to flexural strength. The results of the F-test in Table 9 indicate that at $95 \%$ 575 confidence, the relations developed were significant $(p<0.05)$ for compressive, tensile splitting and 576 flexural strengths at all the four test durations investigated while no evidence of a significant relationship 577 was found for modulus of elasticity and flexural toughness $(p>0.05)$. This suggests that compressive, 578 tensile splitting and flexural strengths may be suitable for predicting concrete abrasion. Figures 15 to 57917 show the capability of the equations proposed in Table 9 to predict the measured concrete abrasion 580 loss. It can be observed that the residuals, i.e. the difference between predicted and measured concrete 581 abrasion loss values were higher for compressive strength in comparison to flexural and tensile splitting 582 strength. While there was no clear relation between the residuals and any of the three concrete parameters, the residuals tended to be highest at a test duration of 72 hours. The lowest residuals were

584 585 586 obtained when concrete abrasion loss was predicted using tensile splitting strength. Most of the residual values were in the range of $\pm 0.50 \%$ in the case of the tensile splitting strength and rest of the data was within $\pm 0.63 \%$.

Therefore, for the range of concretes tested, tensile splitting strength appears to be the most capable parameter for prediction of abrasion resistance. Equations (3) to (6) are therefore proposed to predict $\%$ abrasion loss $\left(V_{a b r, t}\right)$ of the concretes tested based on their tensile splitting strength ( $T$ in $\left.M P a\right)$ at test durations of $12,24,48$ and 72 hours.

$$
\begin{gathered}
\mathrm{V}_{\mathrm{abr}, 12}=5.36-2.00 \mathrm{~T}+0.21 \mathrm{~T}^{2} \\
\mathrm{~V}_{\mathrm{abr}, 24}=8.74-3.32 \mathrm{~T}+0.36 \mathrm{~T}^{2} \\
\mathrm{~V}_{\mathrm{abr}, 48}=12.02-4.26 \mathrm{~T}+0.43 \mathrm{~T}^{2} \\
\mathrm{~V}_{\mathrm{abr}, 72}=10.74-2.96 \mathrm{~T}+0.25 \mathrm{~T}^{2}
\end{gathered}
$$

The reason for the better predictions of concrete abrasion losses from tensile splitting strength compared to compressive strength is not obvious given that the two parameters are often considered to be related (Oloukun 1991; Raphael 1984). One probable explanation for this trend is the similarity in the mechanisms of concrete material removal in the ASTM C1138 test method and the cracking patterns developed during the tensile splitting test. When brittle materials such as concrete are impacted by hard solids, the material is removed from the exposed surface through the development, propagation and intersection of vertical surface and horizontal sub-surface cracks (Vassou et al. 2008). Based on Hertz's equations for elastic contact between solid bodies, the development of surface cracks in brittle materials is attributed to tensile stress while sub-surface cracks are due to shear stress (Burwell 1957; Finnie 
1960; Jacobsen et al. 2015; Johnson 1985). This indicates that increased tensile and shear strengths of concrete enhance its abrasion resistance by reducing the rate of development, propagation and intersection of tensile and shear cracks within the structure of the concrete material.

\section{SUMMARY AND CONCLUSIONS}

This paper used eight concrete mixtures to compare the relationship between the abrasion resistance of concrete and its various mechanical properties, i.e. compressive, tensile splitting, and flexural strengths, as well as modulus of elasticity and flexural toughness. Further, the concrete mixtures used enabled the influence of the quantity and type of coarse aggregates and introduction of rubber particles as a replacement for natural coarse aggregates on concrete abrasion resistance to be evaluated. An analysis of the ASTM C1138 test data showed that the method produces repeatable abrasion results with coefficients of variations of up to $30 \%$. Within the context of the range of concretes and coarse aggregates types used, this work offers the following new insights:

1. The increase of coarse aggregate content in concrete above the dosage recommended for a compressive strength-based mixture design has no significant effect on the abrasion resistance of normal-strength concretes. Further investigations should be undertaken for high-strength concretes.

2. The use of rubber particles with aspect ratios $\sim 4$ in concrete to replace $25 \%$ (by weight) of natural coarse aggregates significantly improves its abrasion resistance by 42 to $64 \%$ at test durations of 24 to 72 hours. The enhanced performance is attributable to the better energy absorption capacity of rubber particles, as well as the presence of a flexible component of surface roughness (due to rubber particles) which contributes to flow energy attenuation in the test.

3. Concrete abrasion resistance of concrete mixtures with $10 \mathrm{~mm}$ rounded coarse aggregates was significantly greater than that of $20 \mathrm{~mm}$ angular coarse aggregates of similar Mohs hardness by 32 to $57 \%$ all test durations. This was explained by the dense packing of particles in $10 \mathrm{~mm}$ aggregates which minimised the area of matrix exposed to abrasion action.

4. The use of tensile splitting strength results in the best prediction of concrete abrasion resistance in the ASTM C1138 test. The empirical relations in Equations (3) to (6) which are applicable to the concrete mixtures tested are proposed for the prediction of abrasion. The relations established predict percent concrete abrasion loss within $\pm 0.5 \%$. 
628 5. There is need for further research in the following areas. Long-term behaviour of rubber-aggregate

629

630

631

632

633

634

635

636

637

638

639

640

641

642

643

644

645

646

647

648

649

650

651

652

653

654 concretes in hydrodynamic environments to provide confidence in their use in field conditions, the relationship between concrete abrasion loss and abrasive charge properties for optimisation of the coarse aggregate size based on the characteristics of the abrasive sediments present in a specific field environment, and the influence of aggregate size and grading on the concrete resistance to abrasion damage. Further, there is need to develop practical empirical relations for prediction of concrete abrasion resistance from its basic mechanical properties based on a large set of published test data.

\section{DATA AVAILABILITY STATEMENT}

All data, models, and code generated or used during the study appear in the submitted article

\section{ACKNOWLEDGEMENTS}

The work presented here is part of wider research project by the authors. The authors wish to express their gratitude and sincere appreciation to the Department of Mechanical, Aerospace and Civil Engineering (MACE), University of Manchester for funding this research, CEMEX UK, Elkem AS (Norway), and Sika UK Ltd for supplying some of the materials used; Mr Brian Farrington (Belfour Beatty, UK), Mr Paul Nedwell and Mr John Mason (MACE) for advice and assistance with the experimental work.

\section{REFERENCES}

ACI Committee 207. (2017). Report on the erosion of concrete in hydraulic structures. American Concrete Institute, Farmington Hills.

ACI Committee 363. (2010). Report on high-strength concrete. Farmington Hills.

ASTM C1138. (2012). Standard test method for abrasion resistance of concrete (Underwater method). Annual Book of ASTM Standards, ASTM International, West Conshohocken.

ASTM C150. (1978). Specification for Portland cement. West Conshohocken.

Branston, J., Das, S., Kenno, S. Y., and Taylor, C. (2016). "Mechanical behaviour of basalt fibre reinforced concrete." Construction and Building Materials, Elsevier Ltd, 124, 878-886.

BS 6349-1-4. (2013). Maritime works: General - Code of practice for materials. British Standards Institution, London. 
BS EN 12390-13. (2013). Testing hardened concrete. Determination of secant modulus of elasticity in compression. British Standards Institution, London.

BS EN 12390-3. (2009). Testing hardened concrete. Compressive strength of test specimens. British Standards Institution, London.

BS EN 12390-6. (2009). Testing hardened concrete. Tensile splitting strength of test specimens. British Standards Institution, London.

BS EN 12390. (2009). Testing hardened concrete Part 5: Flexural strength of test specimens. British Standards Institution, London.

BS EN 12620. (2002). Aggregates for concrete. British Standards Institution, London.

BS EN 197-1. (2011). Cement. Composition, specifications and conformity criteria for common cements. British Standards Institution, London.

BS EN 1990. (2002). Eurocode - Basis of structural design. British Standards Institution, London.

Burwell, J. T. (1957). "Survey of possible wear mechanisms." Wear, 1(2), 119-141.

CAN3-A5-M83. (1983). Portland cements. Standards Council of Canada, Ottawa.

Carollo, F. G., Ferro, V., and Termini, D. (2002). "Flow velocity measurements in vegetated channels." Journal of Hydraulic Engineering, 128(7), 664-673.

Chen, Y., and Kao, S. (2011). "Velocity distribution in open channels with submerged aquatic plant." Hydrological Processes, 25(13), 2009-2017.

Choi, S., and Bolander, J. E. (2012). "A topology measurement method examining hydraulic abrasion of high workability concrete." KSCE Journal of Civil Engineering, 16(5), 771-778.

Cross, W. M., Sabnis, K. H., Kjerengtroen, L., and Kellar, J. J. (2000). "Microhardness testing of fiberreinforced cement paste." ACI Materials Journal, 97(2), 162-167.

Cunningham, L., and Burgess, A. (2012). "Design and construction of the tower headland wave walls, Blackpool, UK." Proceedings of the Institution of Civil Engineers - Civil Engineering, 165(CE4), $171-178$.

Cunningham, L., Robertshaw, G., and Pomfret, M. (2012). "Blackpool central area coast protection scheme, UK." Proceedings of the Institution of Civil Engineers: Maritime Engineering, 165(MA1), 
Cunningham, L. S., Farrington, B., and Doherty, A. (2015). "Briefing: Abrasion performance of concrete in coastal structures." Proceedings of the Institution of Civil Engineers: Maritime Engineering, London, 168, 157-161.

Finnie, I. (1960). "Erosion of surfaces by solid particles." Wear, 3(2), 87-103.

GB175. (2007). Chinese Standard: Common Portland cement. Beijing, China.

Hasparyk, N. P., Monteiro, P. J. M., and Carasek, H. (2000). "Effect of silica fume and rice husk ash on alkali-silica reaction." ACI Materials Journal, 97(4), 486-492.

Hayter, A. (2012). Probability and Statistics for Engineers and Scientists. Brooks/Cole, Boston.

Horszczaruk, E. (2005). "Abrasion resistance of high-strength concrete in hydraulic structures." Wear, 259(1-6), 62-69.

Horszczaruk, E., and Brzozowski, P. (2017). "Effects of fluidal fly ash on abrasion resistance of underwater repair concrete." Wear, Elsevier B.V., 376-377, 15-21.

Horszczaruk, E. K. (2009). "Hydro-abrasive erosion of high performance fiber-reinforced concrete." Wear, 267(1-4), 110-115.

697

Jacobsen, S., Scherer, G. W., and Schulson, E. M. (2015). "Concrete-ice abrasion mechanics." Cement 698 and Concrete Research, Elsevier Ltd, 73(2015), 79-95.

Johnson, K. L. (1985). Contact mechanics. Cambridge University Press, Cambridge.

Kang, J., Zhang, B., and Li, G. (2012). "The abrasion-resistance investigation of rubberized concrete." Journal Wuhan University of Technology, Materials Science Edition, 27(6), 1144-1148.

Kouwen, N., Unny, T. E., and Hill, H. M. (1969). "Flow retardance in vegetated channels." Journal of the Irrigation and Drainage Division, 95(2), 329-344.

Kryžanowski, A., Mikoš, M., Šušteršič, J., and Planinc, I. (2009). "Abrasion resistance of concrete in hydraulic structures." ACI Materials Journal, 106(4), 349-356.

De Larrard, F., and Belloc, A. (1997). "The influence of aggregate on the compressive strength of normal and high-strength concrete." ACI Materials Journal, 94(5), 417-425. 
Liu, T. C. (1981). "Abrasion resistance of concrete." ACl Journal, 78(5), 341-350.

709

710

711

Liu, T. C., and McDonald, J. E. (1981). "Abrasion-erosion resistance of fiber-reinforced concrete." Cement, Concrete and Aggregates, 3(2), 93-100.

Oloukun, F. A. (1991). "Prediction of concrete tensile strength from compressive strength: Evaluation of existing relations for normal weight concrete." ACI Materials Journal, 88(3), 302-309.

Omoding, N., Cunningham, L. S., and Lane-Serff, G. F. (2020). "Review of concrete resistance to abrasion by waterborne solids." ACI Materials Journal, 117(3).

Proverbio, E. (2001). "Stability of reference electrodes embedded in concrete: A statistical evaluation." Magazine of Concrete Research, 53(4), 225-232.

Raphael, J. (1984). "Tensile strength of concrete." ACl Journal, 81(2), 158-165.

RILEM TC89-FMT. (1990). "Determination of fracture parameters (K Ic s and CTODc) of plain concrete using three-point bend tests." Materials and Structures, 23(6), 457-460.

SL 352. (2006). Test code for hydraulic concrete (in Chinese). China Water Power Press, Beijing.

Sonebi, M., and Khayat, K. (2001). "Testing abrasion resistance of high-strength concrete." Cement, Concrete and Aggregates, 23(1), 34-43.

Teychenne, D., Nicholls, J., Franklin, R., and Hobbs, D. (1997). Design of normal concrete mixes. Building Research Establishment, Watford.

Thomas, B. S., Kumar, S., Mehra, P., Gupta, R. C., Joseph, M., and Csetenyi, L. J. (2016). "Abrasion resistance of sustainable green concrete containing waste tire rubber particles." Construction and Building Materials, Elsevier Ltd, 124(2016), 906-909.

Vassou, V. C., Short, N. R., and Kettle, R. J. (2008). "Microstructural investigations into the abrasion resistance of fiber-reinforced concrete floors." Journal of Materials in Civil Engineering, 20(2), $157-168$.

Wang, L., Yang, H. Q., Dong, Y., Chen, E., and Tang, S. W. (2018). "Environmental evaluation, hydration, pore structure, volume deformation and abrasion resistance of low heat Portland (LHP) cement-based materials." Journal of Cleaner Production, Elsevier Ltd, 203, 540-558.

Wentworth, C. K. (1922). "A scale of grade and class terms for clastic sediments." The Journal of 
Young, B. ., and Millman, A. . (1964). "Microhardness and deformation characteristics of ore minerals."

Transactions of the Institution of Mining and Metallurgy, (73), 437-466.

\section{TABLES AND FIGURES}

List of tables:

Table 1. Relative density and water absorption of coarse aggregates

Table 2. Properties of polypropylene micro-fibres

Table 3. Proportioning of concrete mixtures

Table 4. Details of basic mechanical properties of concrete tested

Table 5. Mechanical properties of the concrete mixtures

Table 6. Deviations in concrete abrasion loss measurements

Table 7. Kruskal-Wallis ANOVA test results

Table 8. Kruskal-Wallis ANOVA and Mann-Whitney tests on the mechanical properties of concrete

Table 9. Relations between concrete abrasion loss and its mechanical properties

774 Table 1. Relative density and water absorption of coarse aggregates

\begin{tabular}{|l|c|c|}
\hline Aggregate & Relative density & Water absorption (\%) \\
\hline Bunter quartzite & 2.59 & 0.6 \\
\hline Crushed andesite hornfels & 2.84 & 0.5 \\
\hline Fine aggregates & 2.62 & 0.5 \\
\hline
\end{tabular}

List of figures:

Figure 1. Stepped concrete coastal defence revetment armour units abraded by pebbles (shingle)

Figure 2. Size and shape of recycled rubber aggregates

Figure 3. Particle size distribution of natural concrete aggregates

Figure 4. ASTM C1138 (underwater) test- (a) Laboratory setup; (b) Agitation paddle and (c) Schematic setup.

Figure 5. Flexural strength test- (a) Laboratory setup; (b) LVDT and (c) Schematic setup.

Figure 6. Abrasion loss at 12, 24, 48 and 72 hours

Figure 7. Gradation of combined fine and coarse aggregates

Figure 8. Matrix area bound by coarse aggregates

Figure 9. Damaged concrete surfaces at 72 hours- (a) natural coarse aggregates and (b) incorporating rubber-aggregates

Figure 10. Relationship between abrasion loss and compressive strength

Figure 11. Relationship between abrasion loss and tensile splitting strength

Figure 12. Relationship between abrasion loss and modulus of elasticity

Figure 13. Relationship between abrasion loss and flexural strength

Figure 14. Relationship between abrasion loss and flexural toughness

Figure 15. Relation between compressive strength and residuals obtained from formulas in Table 9

Figure 16. Relation between tensile splitting strength and residuals obtained from formulas in Table 9

Figure 17. Relation between flexural strength and residuals obtained from formulas in Table 9

Table 2. Properties of polypropylene micro-fibres

\begin{tabular}{|l|c|}
\hline Length $(\mathrm{mm})$ & 12 \\
\hline Diameter $(\mu \mathrm{m})$ & 18 \\
\hline Density $\left(\mathrm{kg} / \mathrm{m}^{3}\right)$ & 910 \\
\hline Tensile strength $(\mathrm{MPa})$ & $650 \pm 50$ \\
\hline Modulus of elasticity $(\mathrm{GPa})$ & $3.25 \pm 0.25$ \\
\hline Elongation $(\%)$ & $22.5 \pm 2.5$ \\
\hline
\end{tabular}


Table 3. Proportioning of concrete mixtures

\begin{tabular}{|c|c|c|c|c|c|c|c|c|c|c|}
\hline & Unit & C1 & $\mathrm{C} 2$ & C3 & $\mathrm{C} 4$ & C5 & C6 & $\mathrm{C} 7$ & C8 \\
\hline \multicolumn{2}{|c|}{ Water/binder ratio } & - & 0.80 & 0.80 & 0.80 & 0.62 & 0.52 & 0.52 & 0.44 & 0.44 \\
\hline \multirow[t]{2}{*}{ Binders } & Cement & \multirow{8}{*}{$\mathrm{kg} / \mathrm{m}^{3}$} & 280 & 280 & 280 & 355 & 423 & 423 & 400 & 400 \\
\hline & Silica fume slurry & & - & - & - & - & - & - & 80 & 80 \\
\hline $\begin{array}{l}\text { Fine } \\
\text { aggregates }\end{array}$ & Natural sand & & 850 & 701 & 601 & 753 & 706 & 706 & 684 & 684 \\
\hline \multirow{3}{*}{$\begin{array}{l}\text { Coarse } \\
\text { aggregates }\end{array}$} & Bunter Quartzite & & 995 & 1144 & 1244 & 998 & 976 & 830 & - & 1106 \\
\hline & Hornfels & & - & - & - & - & - & - & 1106 & \\
\hline & Rubber & & - & - & - & - & - & 146 & - & - \\
\hline \multicolumn{2}{|c|}{ Polypropylene micro-fibres } & & - & - & - & - & - & - & 0.9 & 0.9 \\
\hline \multicolumn{2}{|c|}{ Water reducer } & & - & - & - & - & - & - & 3.2 & 3.2 \\
\hline
\end{tabular}

777 Table 4. Details of basic mechanical properties of concrete tested

\begin{tabular}{|l|l|l|c|}
\hline Test parameter & Test method & Test specimen description & $\begin{array}{l}\text { Number of } \\
\text { samples }\end{array}$ \\
\hline Compressive strength & (BS EN 12390-3 2009) & $100 \mathrm{~mm}$ cubes & 9 \\
\hline Tensile splitting strength & (BS EN 12390-6 2009) & $100 \Phi \times 200 \mathrm{~mm}$ cylinders & 3 \\
\hline Modulus of elasticity & (BS EN 12390-13 2013) & $100 \Phi \times 200 \mathrm{~mm}$ cylinders & 3 \\
\hline
\end{tabular}

779 Table 5. Mechanical properties of the concrete mixtures

\begin{tabular}{|c|c|c|c|c|c|c|c|c|}
\hline Mechanical parameter & C1 & $\mathrm{C} 2$ & C3 & C4 & C5 & C6 & C7 & C8 \\
\hline Compressive strength (MPa) & $\begin{array}{l}22.7 \\
(2.8) \\
\end{array}$ & $\begin{array}{l}22.7 \\
(3.3)\end{array}$ & $\begin{array}{l}20.2 \\
(8.4) \\
\end{array}$ & $\begin{array}{l}39.6 \\
(5.7) \\
\end{array}$ & $\begin{array}{l}44.1 \\
(3.7) \\
\end{array}$ & $\begin{array}{l}18.7 \\
(5.3) \\
\end{array}$ & $\begin{array}{l}65.7 \\
(3.6) \\
\end{array}$ & $\begin{array}{l}61.5 \\
(9.3) \\
\end{array}$ \\
\hline Tensile splitting strength (MPa) & $\begin{array}{l}2.65 \\
(9.7)\end{array}$ & $\begin{array}{l}2.70 \\
(5.3) \\
\end{array}$ & $\begin{array}{l}2.50 \\
(8.9) \\
\end{array}$ & $\begin{array}{l}3.25 \\
(9.5)\end{array}$ & $\begin{array}{l}3.95 \\
(7.9) \\
\end{array}$ & $\begin{array}{l}2.10 \\
(9.6) \\
\end{array}$ & $\begin{array}{l}5.25^{*} \\
(5.5)\end{array}$ & $\begin{array}{l}5.20 \\
(1.4) \\
\end{array}$ \\
\hline Modulus of elasticity (GPa) & $\begin{array}{l}24.6 \\
(8.1)\end{array}$ & $\begin{array}{l}31.8 \\
(7.5)\end{array}$ & $\begin{array}{l}26.9 \\
(4.4)\end{array}$ & $\begin{array}{l}28.8 \\
(2.9)\end{array}$ & $\begin{array}{l}29.2 \\
(9.0)\end{array}$ & $\begin{array}{l}19.4 \\
(9.3)\end{array}$ & $\begin{array}{c}39.3 \\
(10.1)\end{array}$ & $\begin{array}{l}36.4 \\
(3.0)\end{array}$ \\
\hline Flexural strength (MPa) & $\begin{array}{c}3.4 \\
(6.0) \\
\end{array}$ & $\begin{array}{c}3.4 \\
(0.0) \\
\end{array}$ & $\begin{array}{c}3.5 \\
(4.9) \\
\end{array}$ & $\begin{array}{c}4.7 \\
(4.6) \\
\end{array}$ & $\begin{array}{c}5.4 \\
(6.9) \\
\end{array}$ & $\begin{array}{c}3.0 \\
(4.2) \\
\end{array}$ & $\begin{array}{c}6.1 \\
(2.7) \\
\end{array}$ & $\begin{array}{r}6.0 \\
(5.6) \\
\end{array}$ \\
\hline Flexural toughness $^{\dagger}(\mathrm{Nmm})$ & $\begin{array}{l}582 \\
(7.8) \\
\end{array}$ & $\begin{array}{c}667 \\
(18.1)\end{array}$ & $\begin{array}{c}647 \\
(11.4) \\
\end{array}$ & $\begin{array}{c}954 \\
(7.0) \\
\end{array}$ & $\begin{array}{c}1003 \\
(12.1)\end{array}$ & $\begin{array}{l}569 \\
(4.9) \\
\end{array}$ & - & - \\
\hline $\begin{aligned} \text { Notes 1: } & (-) \text { denotes post-cra } \\
\text { 2: } & \left({ }^{*}\right) \text { denotes test res } \\
\text { 3: } & (\dagger) \text { load versus crac }\end{aligned}$ & & & & & ecimens & & & \\
\hline
\end{tabular}

780 Table 6. Deviations in concrete abrasion loss measurements

\begin{tabular}{|c|c|c|c|c|}
\hline \multirow{2}{*}{$\begin{array}{c}\text { Concrete } \\
\text { mixture }\end{array}$} & \multicolumn{4}{|c|}{ Coefficients of variation (\%) } \\
\cline { 2 - 5 } & $12 \mathrm{~h}$ & $24 \mathrm{~h}$ & $48 \mathrm{~h}$ & $72 \mathrm{~h}$ \\
\hline C1 & 8.3 & 16.2 & 7.2 & 6.8 \\
\hline C2 & 3.8 & 14.8 & 2.7 & 10.1 \\
\hline C3 & 21.7 & 18.5 & 12.1 & 7.7 \\
\hline C4 & 1.6 & 13.5 & 29.2 & 20.4 \\
\hline C5 & 22.2 & 19.3 & 17.5 & 13.4 \\
\hline C6 & 7.6 & 7.1 & 7.8 & 14.7 \\
\hline C7 & 13.6 & 12.1 & 1.3 & 6.1 \\
\hline C8 & 19.9 & 19.4 & 17.2 & 7.2 \\
\hline
\end{tabular}

781 Table 7. Kruskal-Wallis ANOVA test results

\begin{tabular}{|c|c|c|c|}
\hline $\begin{array}{c}\text { Test duration } \\
\text { (hours) }\end{array}$ & $\mathrm{X}^{2}$ & DF & $\mathrm{p}$-value \\
\hline 12 & 5.60 & & 0.061 \\
\hline 24 & 4.36 & \multirow{2}{*}{2} & 0.113 \\
\hline 48 & 0.69 & & 0.707 \\
\hline 72 & 4.36 & & 0.113 \\
\hline & & & \\
\hline
\end{tabular}


Table 8. Kruskal-Wallis ANOVA and Mann-Whitney tests on the mechanical properties of concrete

\begin{tabular}{|c|c|c|c|c|c|c|c|}
\hline \multirow[t]{3}{*}{ Mechanical property } & \multicolumn{3}{|c|}{ CA quantity } & \multicolumn{2}{|c|}{ Rubber addition } & \multicolumn{2}{|c|}{ CA type } \\
\hline & \multicolumn{3}{|c|}{$\begin{array}{c}\text { Kruskal-Wallis ANOVA } \\
\text { test }\end{array}$} & \multicolumn{2}{|c|}{$\begin{array}{l}\text { Mann-Whitney } \\
\text { test }\end{array}$} & \multicolumn{2}{|c|}{$\begin{array}{l}\text { Mann-Whitney } \\
\text { test }\end{array}$} \\
\hline & $X^{2}$ & $D F$ & $p$-value & $U$ & $p$-value & $U$ & $p$-value \\
\hline Compressive strength & 11.27 & \multirow{5}{*}{2} & 0.004 & 81 & $2.05 \times 10^{-4}$ & 55 & 0.108 \\
\hline Tensile splitting strength & 1.69 & & 0.430 & \multirow{4}{*}{9} & \multirow{4}{*}{0.040} & 3 & 0.613 \\
\hline Modulus of elasticity & 6.31 & & 0.043 & & & 7 & 0.191 \\
\hline Flexural strength & 0.03 & & 0.987 & & & 5.5 & 0.747 \\
\hline Flexural toughness & 1.69 & & 0.430 & & & - & - \\
\hline
\end{tabular}

Table 9. Relations between concrete abrasion loss and its mechanical properties

\begin{tabular}{|c|c|c|c|c|c|c|}
\hline Mechanical & $\begin{array}{c}\text { Duration } \\
\text { (hours) }\end{array}$ & Regression equations & $\mathrm{R}^{2}$ & $\begin{array}{c}\mathrm{DF} \\
(1,2)\end{array}$ & F-value & P-value \\
\hline \multirow{4}{*}{$\begin{array}{l}\text { Compressive } \\
\text { strength }(\mathrm{C})\end{array}$} & 12 & $2.91-0.07 \mathrm{C}+0.0006 \mathrm{C}^{2}$ & 0.87 & \multirow{4}{*}{2,4} & 12.99 & 0.018 \\
\hline & 24 & $4.66-0.12 C+0.001 C^{2}$ & 0.83 & & 9.87 & 0.028 \\
\hline & 48 & $6.61-0.15 C+0.001 C^{2}$ & 0.93 & & 28.51 & 0.004 \\
\hline & 72 & $6.48-0.09 C+0.0003 C^{2}$ & 0.78 & & 7.16 & 0.048 \\
\hline \multirow{4}{*}{$\begin{array}{l}\text { Tensile } \\
\text { splitting } \\
\text { strength (T) }\end{array}$} & 12 & $5.36-2.00 \mathrm{~T}+0.21 \mathrm{~T}^{2}$ & 0.89 & \multirow{4}{*}{2,4} & 16.28 & 0.012 \\
\hline & 24 & $8.74-3.32 \mathrm{~T}+0.36 \mathrm{~T}^{2}$ & 0.86 & & 12.68 & 0.019 \\
\hline & 48 & $12.02-4.26 \mathrm{~T}+0.43 \mathrm{~T}^{2}$ & 0.97 & & 71.36 & 0.001 \\
\hline & 72 & $10.74-2.96 \mathrm{~T}+0.25 \mathrm{~T}^{2}$ & 0.87 & & 13.14 & 0.017 \\
\hline \multirow{4}{*}{$\begin{array}{l}\text { Modulus of } \\
\text { elasticity }(E)\end{array}$} & 12 & $10.21-0.51 \mathrm{E}+0.0069 \mathrm{E}^{2}$ & 0.65 & \multirow{4}{*}{2,4} & 3.77 & 0.120 \\
\hline & 24 & $13.53-0.65 \mathrm{E}+0.0086 \mathrm{E}^{2}$ & 0.56 & & 2.51 & 0.196 \\
\hline & 48 & $12.08-0.45 \mathrm{E}+0.0046 \mathrm{E}^{2}$ & 0.52 & & 2.17 & 0.230 \\
\hline & 72 & $2.08+0.25 \mathrm{E}-0.0065 \mathrm{E}^{2}$ & 0.44 & & 1.57 & 0.313 \\
\hline \multirow{4}{*}{$\begin{array}{l}\text { Flexural } \\
\text { strength (F) }\end{array}$} & 12 & $2.82-0.37 \mathrm{~F}$ & 0.84 & \multirow{4}{*}{1,5} & 26.53 & 0.004 \\
\hline & 24 & $4.24-0.53 \mathrm{~F}$ & 0.76 & & 15.63 & 0.011 \\
\hline & 48 & $6.80-0.86 \mathrm{~F}$ & 0.94 & & 81.02 & 0.0003 \\
\hline & 72 & $8.07-0.98 \mathrm{~F}$ & 0.81 & & 21.98 & 0.005 \\
\hline \multirow{4}{*}{$\begin{array}{l}\text { Flexural } \\
\text { toughness }(J)\end{array}$} & 12 & $3.19-0.0030 \mathrm{~J}+\left(6.47 \times 10^{-1}\right) \mathrm{J}^{2}$ & 0.88 & \multirow{4}{*}{2,2} & 7.30 & 0.121 \\
\hline & 24 & $-0.25+0.0089 \mathrm{~J}-\left(7.30 \times 10^{-6}\right) \mathrm{J}^{2}$ & 0.71 & & 2.49 & 0.287 \\
\hline & 48 & $-5.78+0.0280 \mathrm{~J}-\left(2.01 \times 10^{-5}\right) \mathrm{J}^{2}$ & 0.95 & & 18.55 & 0.051 \\
\hline & 72 & $-24.44+0.0784 J-\left(5.10 \times 10^{-5}\right) J^{2}$ & 0.86 & & 6.25 & 0.138 \\
\hline
\end{tabular}

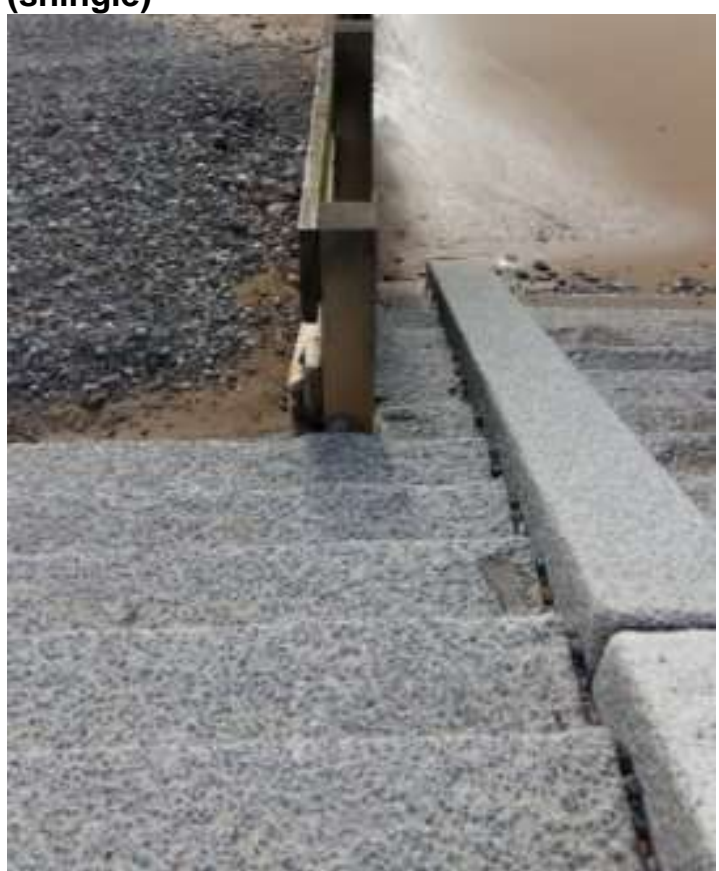


Figure 2. Size and shape of recycled rubber aggregates

789

790

791

792

793

794

795

796

797

798

799

800

801

802

803

804

805

806

807

808

809

810

811

812

813

814

815

816

817

818

819

Figure 3. Particle size distribution of natural concrete aggregates

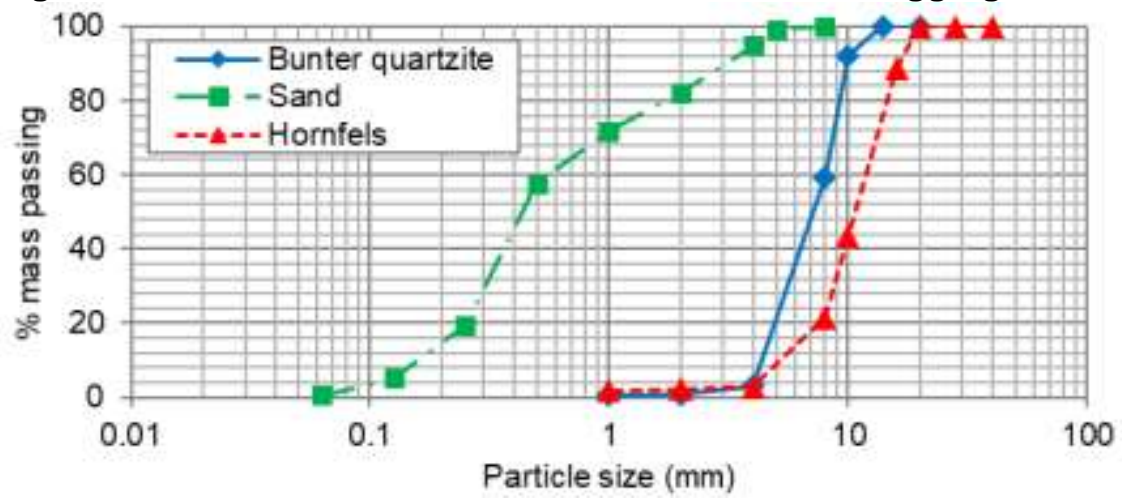


Figure 4. ASTM C1138 (underwater) test- (a) Laboratory setup; (b) Agitation paddle and (c)

Schematic setup.

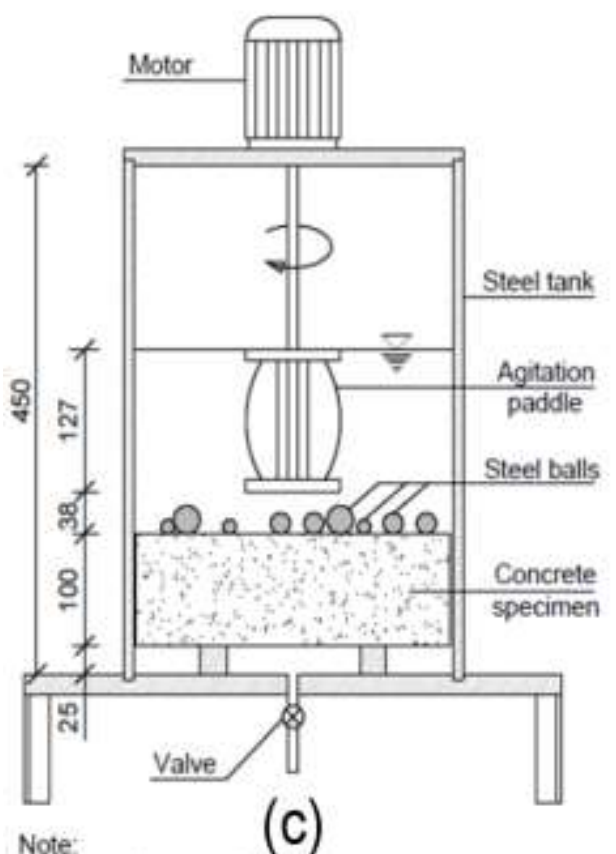

(c)

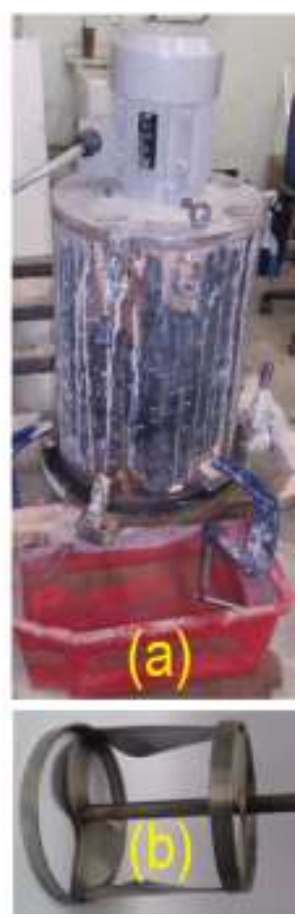

All dimensions are in $\mathrm{mm}$

Figure 5. Flexural strength test- (a) Laboratory setup; (b) LVDT and (c) Schematic setup.

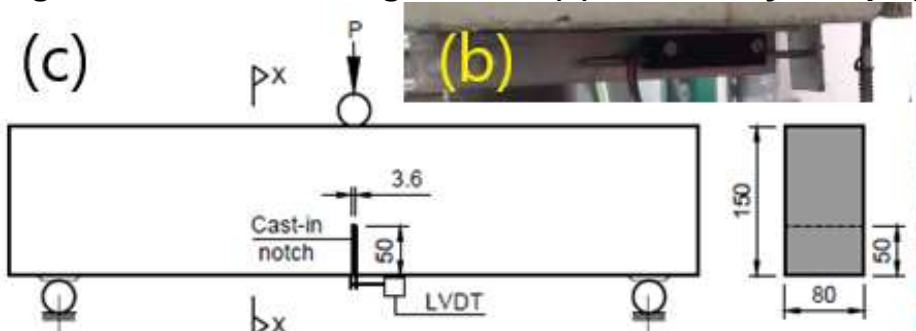

$\underline{x-x}$

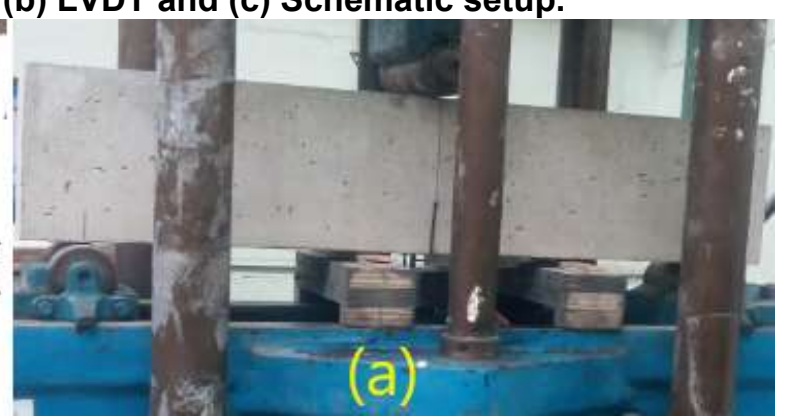

$50 \mid$ 600

$+50$

827

828

Figure 6. Abrasion loss at 12, 24, 48 and 72 hours

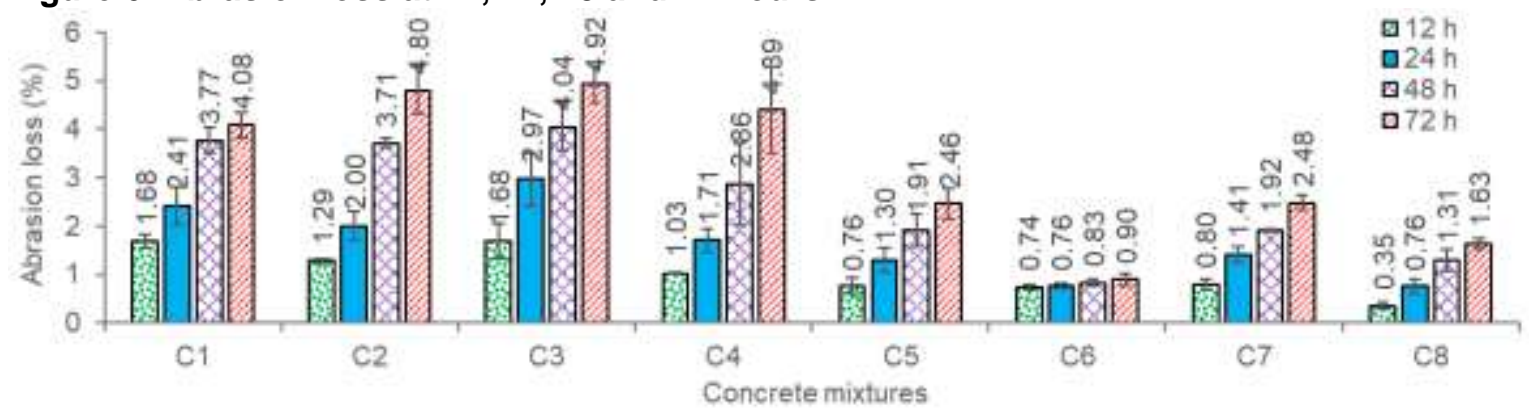


841 Figure 7. Gradation of combined fine and coarse aggregates

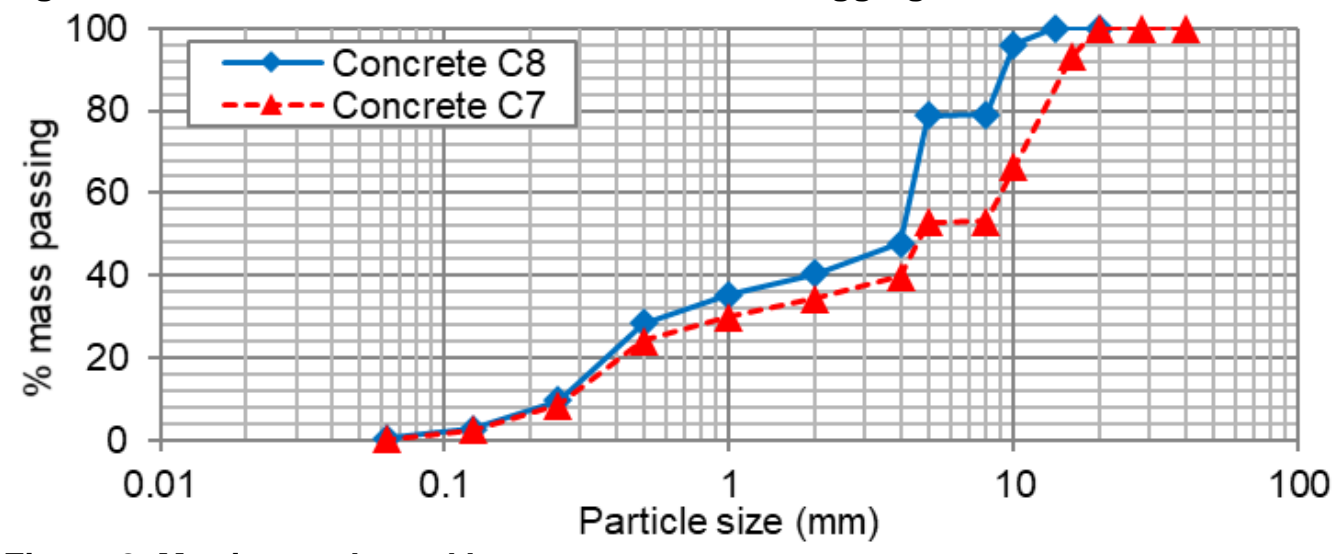

842

Figure 8. Matrix area bound by coarse aggregates

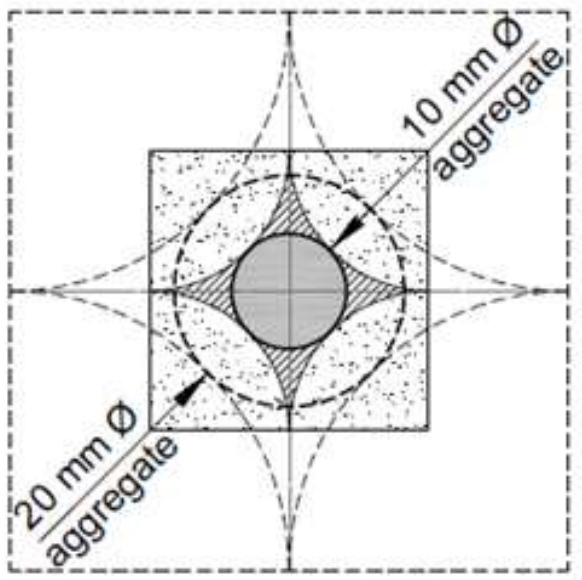

844

845

846

Figure 9. Damaged concrete surfaces at 72 hours- (a) natural coarse aggregates and (b) incorporating rubber-aggregates
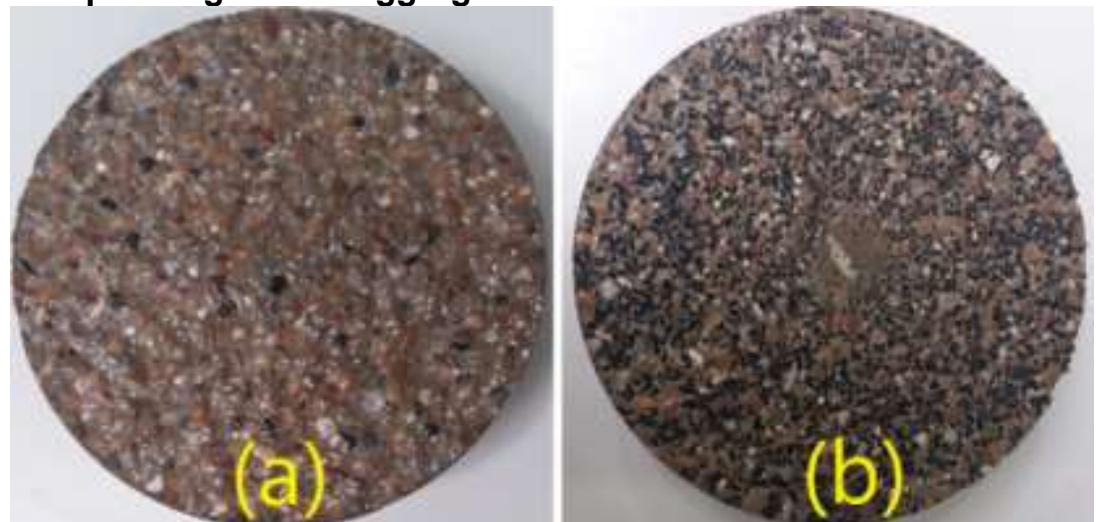

Figure 10. Relationship between abrasion loss and compressive strength

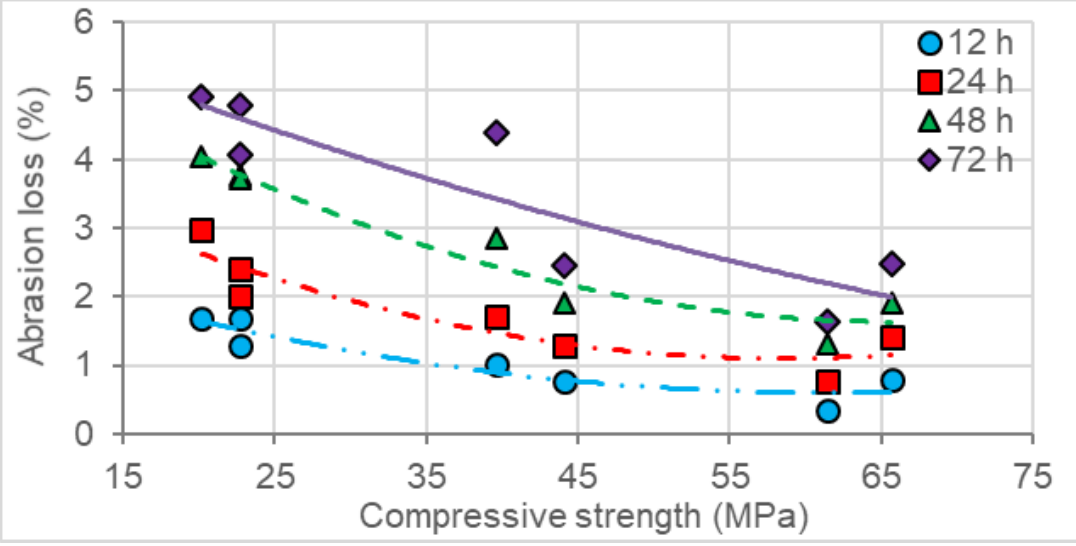


Figure 11. Relationship between abrasion loss and tensile splitting strength

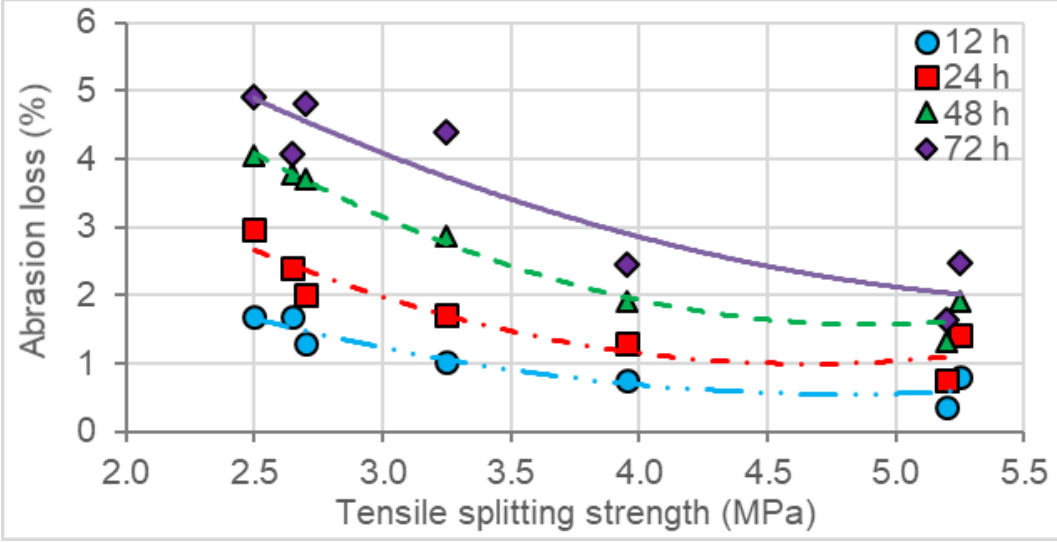

Figure 12. Relationship between abrasion loss and modulus of elasticity

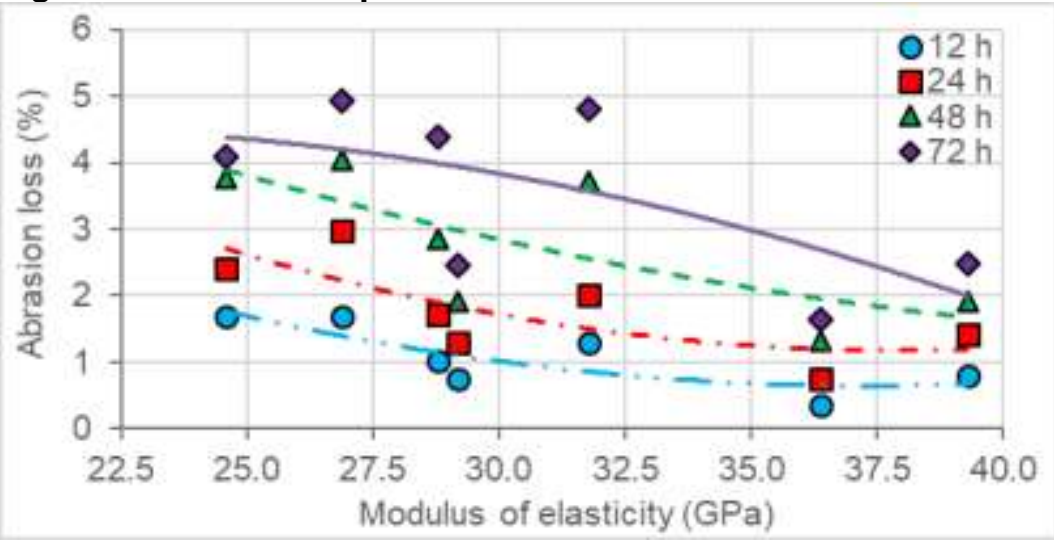

Figure 13. Relationship between abrasion loss and flexural strength

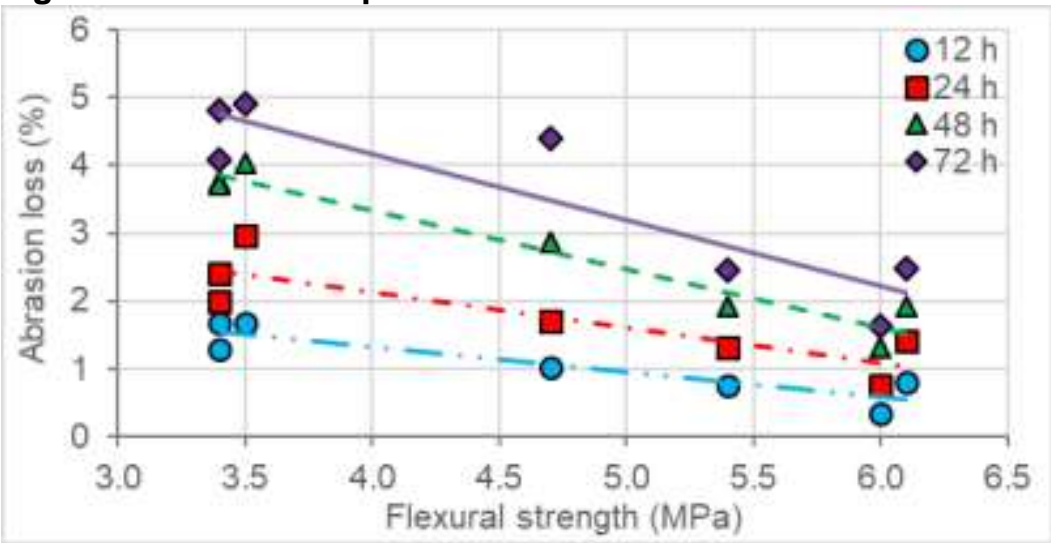

Figure 14. Relationship between abrasion loss and flexural toughness

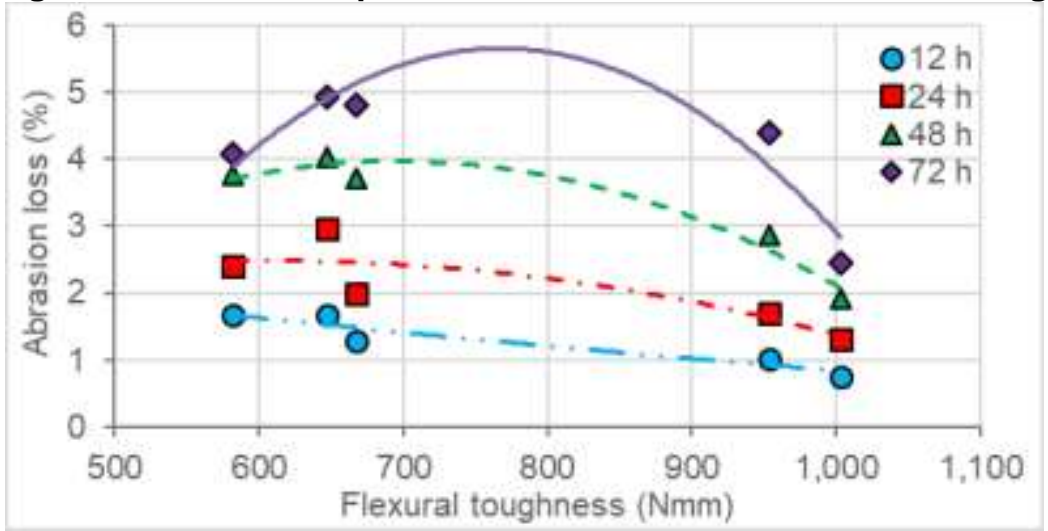


Figure 15. Relation between compressive strength and residuals obtained from formulas in

Table 9

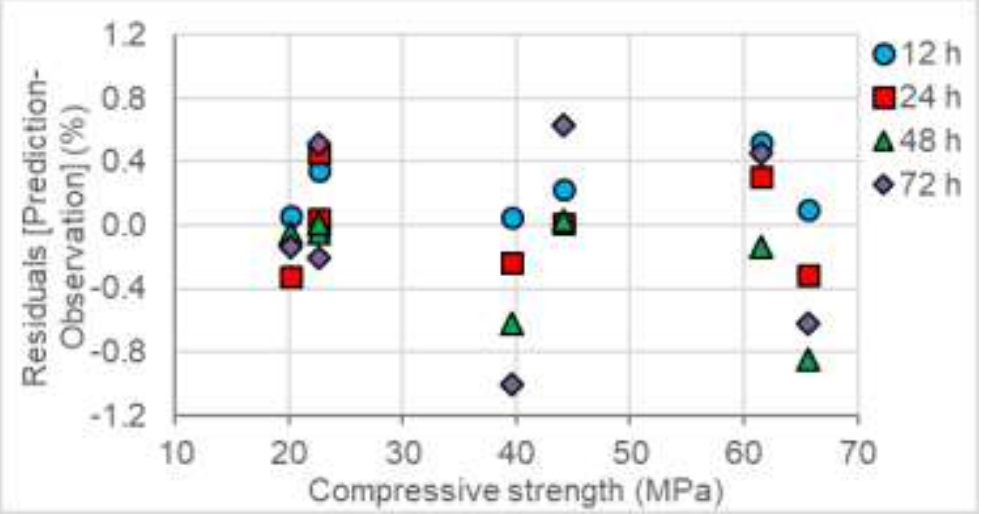

Figure 16. Relation between tensile splitting strength and residuals obtained from formulas in

Table 9

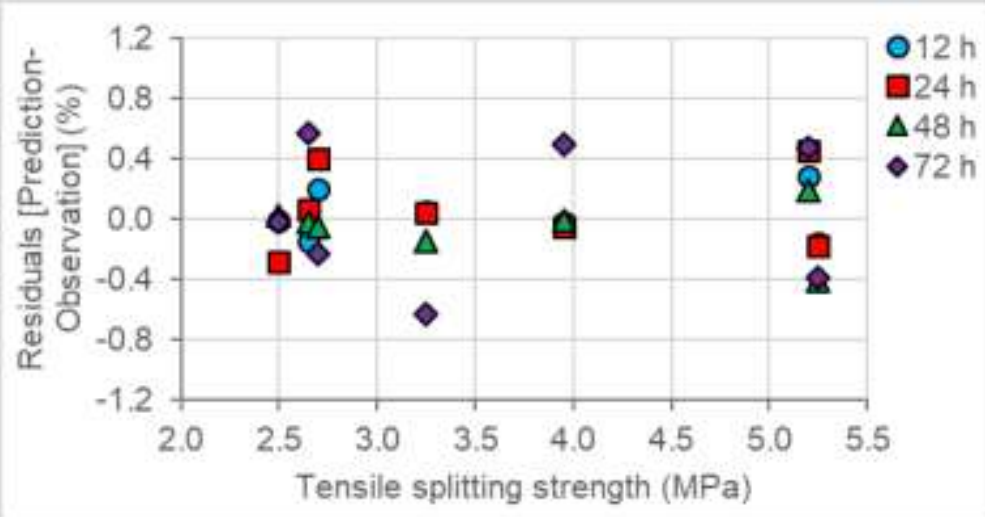

Figure 17. Relation between flexural strength and residuals obtained from formulas in Table 9

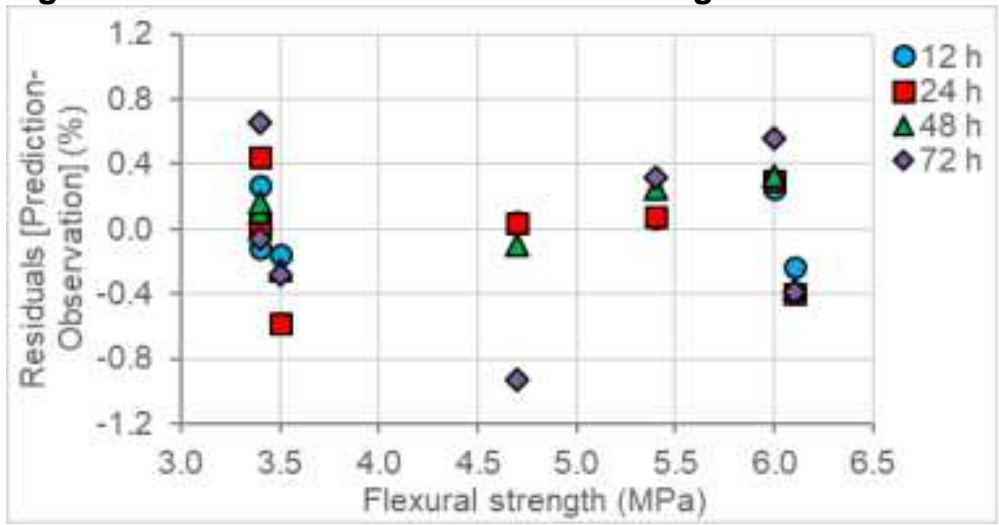

